\title{
Redistribution without distortion: Evidence from an affirmative action program at a large Brazilian university*
}

\author{
Fernanda Estevan ${ }^{\dagger} \quad$ Thomas Gall $^{\ddagger}$ Louis-Philippe Morin ${ }^{\S}$
}

December 29, 2017

\begin{abstract}
We examine an innovative affirmative action policy at UNICAMP, a large and highly ranked Brazilian university, designed to enhance access for disadvantaged (public high school) applicants. The university awarded bonus points to targeted applicants in their admission exam. We assess the effect of this policy on the composition of admitted students and investigate possible behavioural responses in terms of exam-preparation effort. We find that the policy significantly increased the admission probability of public high school applicants and redistributed university admission towards applicants from families with lower socio-economic status. Surprisingly, we find little evidence of behavioural reactions regarding exam-preparation effort.
\end{abstract}

Keywords: post-secondary education, affirmative action, university admission, inequality.

This is the peer reviewed version of the following article: Redistribution without distortion: Evidence from an affirmative action program at a large Brazilian university, The Economic Journal (forthcoming 2018), which has been published in final form at http://www.onlinelibrary.wiley.com/doi/10.1111/ecoj.12578. This article may be used for non-commercial purposes in accordance with Wiley Terms and Conditions for SelfArchiving.

${ }^{*}$ This research was supported by the Social Sciences and Humanities Research Council of Canada (Insight Development Grant, 430-2013-001033), the British Academy and the Newton Fund (Newton Advanced Fellowship, AF140079). We thank Pierre Brochu, Ana Rute Cardoso, Jason Garred, Jackie Wahba, and seminar and conference participants at FGV EESP, FGV EPGE, Heriot-Watt University, Insper, University of Girona, University of Southampton, University of Namur, USP, EBE, SCSE, the CEA, LACEA and RES Meetings for many helpful comments. We are very grateful to the editor, Estelle Cantillon, and two anonymous referees, whose comments substantially improved the article. We also thank Gustavo Katague, Derek Rice, Duangsuda Sopchokchai, Bogdan Urban, Pedro Feitosa, and Tiago Ferraz for their excellent research assistance. All remaining errors are ours.

†Sao Paulo School of Economics - FGV, Rua Itapeva, 474, Sao Paulo, SP, Brazil; email: fernanda.estevan@fgv.br.

$\ddagger$ Department of Economics, School of Social Sciences, University of Southampton, Southampton, SO17 1BJ, UK; email: t.gall@soton.ac.uk.

$\S$ Department of Economics, University of Ottawa, 120 University, Ottawa ON K1N 6N5, Canada; email: lmorin@uottawa.ca. 
Policymakers and academics alike are increasingly concerned about the degree to which socioeconomic background determines educational and occupational outcomes. A crucial factor determining social mobility is access to higher education. The perception that unequal university access may be contributing to unequal opportunities has led to various forms of affirmative action for university admission in many countries. The perceived lack of a level playing field and its proposed policy remedies are not unique to education and extend to other allocation mechanisms, such as auctions and labour market policies. ${ }^{1}$ Whether the proposed remedies can achieve their policy goals and how serious are the distortions they are likely to produce have been at the heart of a lively debate. ${ }^{2}$

Policies that redistribute access to opportunity may trigger behavioural responses in the choice of effort and investments taken at earlier stages. While behavioural responses may be precisely the intended aim of the policy in some cases, such as increasing bids in an auction, they may interfere with the aimed for redistribution in others. Indeed, an often voiced concern in the policy debate in the context of education and labour markets is that those favored by a policy may reduce their effort, profiting from an implicit guarantee, while those not favored will have incentives to work harder (see also Coate and Loury, 1993a; Fryer and Loury, 2013, for possible theoretical reasons for this). Such behaviour could considerably diminish the policy's redistributive impact.

In this paper we examine whether a policy that redistributes access to higher education might be undone, or perhaps amplified, by distortions of individual behaviour regarding exam-preparation effort. To do so, we exploit a quasi-experiment generated by the introduction of an affirmative action policy in admission at UNICAMP (Universidade Estadual de Campinas), a large and highly ranked public university in Brazil. The policy awarded applicants from disadvantaged backgrounds a large bonus on their admission exam score. It was motivated by a concern that private high schools have disproportionate success rates in placing their pupils into selective universities; an issue that is relevant for Brazil, but also for other developing and developed countries. For instance, only 3\% (or 100) of all schools that have university-bound students made up approximately $32 \%$ of the intake of Oxford and Cambridge in 2007-2009 (The Sutton Trust, 2011). Similar patterns have been observed for the Universities of California (Martin et al., 2005) and Texas (Long et al., 2010).

The evidence on possible behavioural reactions to such policies in competitive real-world

\footnotetext{
${ }^{1}$ For instance, in auctions, especially public procurement auctions, sellers use both bidding credits (i.e., subsidies) and set-asides (similar to quotas) to favour small or minority firms, reasoning that these bidders are disadvantaged by higher cost of capital. Similarly, an apparent deficit of equal access to opportunities in the labour market and the political arena has motivated policy responses, most notably reservation in India.

${ }^{2}$ See, e.g., Fryer and Loury (2005) for a discussion surrounding the affirmative-action debate in the United States, and Holzer and Neumark (2000), Arcidiacono et al. (2015) and Arcidiacono and Lovenheim (2016) for reviews of the literature on the impacts of these policies on educational outcomes.
} 
settings is remarkably scarce in the context of higher education. ${ }^{3}$ As effort is typically not observed in non-experimental settings, most studies rely on exam grades. ${ }^{4}$ Assuncao and Ferman (2015) use a differences-in-differences approach to compare standardised exam grades of different cohorts of high school students in Brazilian states that implemented affirmative action policies, or not. They find a substantial decrease in the performance of black students in Rio de Janeiro, a group that benefited from large quotas, in line with predictions from Coate and Loury (1993b). A challenge for this approach is that performance outcomes are measured over the entire population of high school students. Hence, identification of the effect on college-bound applicants relies on this effect being sufficiently homogeneous across the entire student population.

Economic theory suggests heterogeneous behavioural reactions to a policy awarding a sizable bonus to some participants, but not to others. Applying a version of an incomplete information auction model of university admission by Bodoh-Creed and Hickman (2016) to our setting suggests heterogeneous policy effects on exam-preparation effort. In this setting lower academic ability applicants who (do not) receive a bonus increase (decrease) their effort while their higher ability counterparts decrease (increase) it, although the magnitude depends on the convexity of applicants' effort cost function. By contrast, in a two-dimensional matching model with prior investments by Gall et al. (2015), all applicants favoured by the policy increase their effort because the prospect of being matched to better peers increases the return on effort. Those who are not favoured may decrease their effort. Similarly, studies in the auction literature would predict behavioural reactions, for instance, Fryer and Loury (2013) who study a multi-item auction with discrete prior investments or Arozamena and Cantillon (2004) who allow for investments in bidders' types. Affirmative action has also been studied in the theory of tournaments by, e.g., Fu (2006) and Franke (2012). Generally, effects will depend on an individual's position in the distribution, emphasising the need to test for heterogeneous policy effects.

To the best of our knowledge we provide the first direct causal estimation of the impact of affirmative action on college applicants' effort provision allowing for heterogeneous effects across the ability distribution in a real-world environment. The only other paper investigating such potential heterogeneous effects is Bodoh-Creed and Hickman (2017). They rely on

\footnotetext{
${ }^{3}$ Experimental studies present mixed results (see, e.g., Schotter and Weigelt, 1992; Calsamiglia et al., 2013; Cotton et al., 2014), suggesting that effects may be highly dependent on their specific design. Empirical evidence from auctions points to sizable effects in participation and bidding behaviour (e.g. Krasnokutskaya and Seim, 2011; Ayres and Cramton, 1996). Reservation has been found to redistribute access (e.g. Pande, 2003; Chin and Prakash, 2011), but evidence on its effects on education acquisition is scarce.

${ }^{4}$ An exception is Francis and Tannuri-Pianto (2012), who proxy effort by the number of attempts at the admission exam and preparatory course enrollment. They find a small increase in those measures for mulatto (mixed-race) applicants after the University of Brasilia introduced a quota-based affirmative action policy.
} 
structural estimation and U.S. survey data of college graduating students to estimate the effect of preferential university admission on pre-college investment. While their approach can capture effort changes in response to different affirmative action policies, their data impose limitations. In particular, they do not observe the entire population of college enrollees (or applicants), which forces them to use sample-selection correction procedures. The results from their counterfactual experiments show an approximately zero average impact for majority students, but a positive effect for minority students that depends on a student's rank in the SAT distribution.

The design of UNICAMP's admission exam permits us to obtain a clean measure of relative exam-preparation effort by comparing applicants' actual entrance exam score and their predicted exam scores given their characteristics, controlling for a host of observables that include an ability proxy. Our quasi-experimental setting and rich database containing information on all university applicants and enrollees allow us to overcome typical identification concerns in the literature. Moreover, we allow for heterogeneous effects based on applicants' predicted exam scores.

Our results indicate that UNICAMP's affirmative action policy led to a sizable redistribution of access to university: almost $10 \%$ of all admitted applicants would not have been admitted in the absence of the policy; they came from significantly lower socio-economic status backgrounds than the individuals they displaced, and they did not differ significantly in their centralised high school graduation score (ENEM). This alleviates concerns of a dilution of academic quality. ${ }^{5}$ By contrast, visible minority students from private schools, who were not favoured by the policy, suffered a significant decrease in their admission rate relative to their non-visible minority counterparts. These results are in line with previous findings, notably Bertrand et al. (2010) who study a quota-based affirmative action policy targeting lower caste individuals in India.

Interestingly, we do not find evidence of sizable behavioural distortions, and the policy effects are well predicted by ignoring them. The difference in relative performance between public and private high school applicants is essentially zero after introducing the affirmative action policy. ${ }^{6}$

We perform a series of additional exercises to account for heterogeneous effects, informed by the theoretical framework. In particular, we test whether applicants reacted differently

\footnotetext{
${ }^{5}$ Antonovics and Backes (2014) find a modest impact of abandoning affirmative action at the University of California system on GPA of college-bound students. As for college admission, Backes (2012) and Hinrichs (2012) find modest or null effects of the ban on affirmative action on enrollment and graduation of minorities.

${ }^{6}$ Our data makes identification of changes in the applicant pool difficult, but evidence from the end of the race-based affirmative action in the US suggests small changes in application behaviour by minority students (Long, 2004; Dickson, 2006), especially for highly qualified minority students (Card and Krueger, 2005).
} 
based on whether they were predicted to be above or below the admission cutoff grade, and based on their relative distance from this cutoff. We do not find evidence of significant heterogeneity along any of these dimensions. Our results suggest that behavioural responses were too small to be detectable in the data if they occurred at all. This would occur in our theoretical setting if applicants' effort cost functions are sufficiently convex, implying a low elasticity of effort to changes in the payoffs. This seems plausible in light of the highly competitive nature of UNICAMP's admission exam.

The paper is organised as follows. Section 1 discusses UNICAMP admission system, its affirmative action policy, and concurrent policies implemented in Brazil. Section 2 presents simulations of the model by Bodoh-Creed and Hickman (2016). Section 3 describes the data, Section 4 lays out our econometric strategy, and Section 5 presents our results. Section 6 discusses possible general equilibrium effects, and Section 7 concludes.

\section{Institutional Background}

\subsection{UNICAMP's Admission Process}

UNICAMP is a public university in the city of Campinas and state of Sao Paulo, Brazil. It is a large research-intensive university, with half of its 37,000 students at the graduate level. UNICAMP does not charge tuition fees (as is the case for all Brazilian public universities). Together with USP, UNICAMP is considered one of the best universities in the country; hence, admission is valued extremely highly by prospective students. ${ }^{7}$ Applicants are free to apply to both USP and UNICAMP, which is what most individuals do, as well as to other public and private universities.

Admission at UNICAMP is governed by a university-specific entrance exam (vestibular). The exam registration takes place in September, and successful candidates will start university in February of the following year, e.g., applicants who registered to the admission exam "UNICAMP 2005" did so in September 2004. There is a registration fee for the entrance exam, but low-income applicants benefit from a fee waiver. When registering, candidates can apply to up to three majors (which they rank first, second, and third). The number of places offered per major at UNICAMP was quite stable over the period 2003-2008. In 2003, UNICAMP offered 2,814 places in total. In 2004 and 2005 the total number of places increased to 2,934, and then to 2,954 from 2006 on.

\footnotetext{
${ }^{7}$ Universidade de Sao Paulo (USP) is located in Sao Paulo capital, $100 \mathrm{~km}$ away from UNICAMP, and is UNICAMP's main competitor. Among the 142,902 applicants to USP in 2004, only $21.6 \%$ stated they had applied exclusively to USP, and 30\% reported also applying to UNICAMP, which constitutes $88.9 \%$ of UNICAMP's total number of applicants.
} 
The vestibular consists of two parts that are taken in sequential order: the Phase 1 and Phase 2 exams (henceforth referred to as $P_{1}$ and $P_{2}$, respectively). $P_{1}$ and $P_{2}$ exams are taken in November and January of each year, roughly two and four months after the applicant's registration. Only applicants who pass $P_{1}$ (about $30 \%$ of applicants) are allowed to take $P_{2}$. The exams are the same for all applicants (in both $P_{1}$ and $P_{2}$ ), regardless of their choice of major. They consist of open questions (no multiple choice questions) aimed at testing the applicant's mastery of high school compulsory subjects. ${ }^{8}$

The $P_{1}$ exam consists of 12 general questions based on typical high school subjects and an essay. An applicant's score in $P_{1}$ is the maximum of (i) the raw performance on the general questions and the essay, and (ii) a weighted average of that raw performance and the applicant's high school exit exam score ENEM (Exame Nacional do Ensino Medio) with a weight of $20 \%$. The ENEM is a high-stakes centralised end-of-high-school exam that tests basic competencies and abilities and is used by several universities as part of their admission systems. An applicant's ENEM scores only counts for at most $20 \%$ of her $P_{1}$ score, so that a very good performance in the general questions and the essay is essential to advance to $P_{2}$.

An applicant automatically fails $P_{1}$ if she obtains a score of zero in any of its components (i.e., essay and general questions). The cutoff score (nota de corte) for $P_{1}$ is set initially at $50 \%$ but is then adjusted to guarantee that the number of candidates progressing to $P_{2}$ in each major is at least three and at most eight times the number of places offered in that major. Hence, more popular majors will have $P_{1}$ cutoff scores over $50 \%$. The $P_{1}$ cutoff scores are announced publicly in December along with the list of candidates who passed $P_{1}$.

$P_{2}$ is administered over four days and composed of eight parts, each based on a specific (compulsory) high school subject. Applicants automatically fail $P_{2}$ if they receive zero on (or are absent from) any of the eight parts. While $P_{2}$ tests are identical for all majors, the $P_{2}$ final score weighs each of the eight subjects (parts) differently, according to the major applied for. Each major typically has at least one "priority subject," a subject which carries greater weight in the $P_{2}$ score.

The overall admission exam score (NPO, for nota padronizada de opção) is computed using the standardised weighted average of (i) the $P_{1}$ score, (ii) the $P_{2}$ priority subject scores, and (iii) the $P_{2}$ non-priority subject scores. While the $P_{1}$ score and each of the priority subject scores have a weight of 2 in the weighted average, each non-priority subject score has a weight of 1 . Finally, the university ranks candidates in decreasing order of their (major-specific) NPOs to make its admission offers. The small number of available seats

\footnotetext{
${ }^{8}$ Some majors, like Dentistry and Performing Arts, also require an aptitude test as part of $P_{2}$. See Appendix A for more details about the admission process and the way the major choices affect an applicant's rankings.
} 
relative to the number of applicants and the admission test structure makes these $P_{1}$ and $P_{2}$ entrance exams very competitive.

\subsection{UNICAMP's Affirmative Action Policy}

The affirmative action program was implemented in 2004, affecting UNICAMP's 2005 entrance exam. The stated aim of the new policy was to increase admission of public high school graduates, who were underrepresented at UNICAMP. The specific design of the program was based on a study, later published as Pedrosa et al. (2007), showing that public high school graduates performed better in UNICAMP's undergraduate programs than their private school counterparts. The study concluded that public high school graduates could be subject to a lower entrance threshold without significantly compromising their performance at UNICAMP. ${ }^{9}$

Under the new policy applicants who spent their last three years of high school exclusively at a public school can request bonus points at the entrance exam. When registering for the admission exam, applicants fill out an online form and explicitly opt, or not, for the affirmative action policy. The online form includes detailed information about the affirmative action policy, which is also provided in the applicants' manual. Thus, we can be confident that UNICAMP applicants were aware of the existence, design, and eligibility criteria of the affirmative action policy when registering for the entrance exam. ${ }^{10}$

Applicants eligible for the affirmative action policy receive a 30-point bonus on their NPO score, which corresponds to $30 \%$ of a standard deviation. ${ }^{11}$ If these applicants declare themselves as black, mulatto or native, they receive an additional 10 points on their NPO score (for a total of 40 points). Note that black, mulatto or native applicants from private high schools do not receive any bonus.

[ Figure 1 approximately here.]

To assess the significance of a 30 points bonus Figure 1 presents the distributions of NPO scores for applicants both from public and private high schools before the affirmative-action

\footnotetext{
${ }^{9} \mathrm{We}$ do not have access to UNICAMP student performance data (once they are admitted) to verify whether that was indeed the case with the affirmative action policy. Tessler (2006) finds that affirmative action beneficiaries had equal if not higher grades at UNICAMP, considering the initial performance of the two first cohorts admitted through the program.

${ }^{10}$ Since the policy was announced in May 2004, we cannot exclude that some applicants may have learned about the affirmative action policy before registering, through newspapers or other sources. As a robustness check, we split our sample based on whether or not the candidate reads newspapers on a regular basis. Our results remain unchanged if we restrict the sample to candidates who read newspapers (or to those not reading newspapers). These results are available upon request.

${ }^{11}$ According to Pedrosa et al. (2007) and Kleinke (2006), the 30-point bonus was chosen to take into account the relative performance of public and private high school graduates.
} 
policy (2001-2004). Applicants from public high schools performed worse in the admission exam than applicants from private schools. Adding 30 points shifts the distribution of NPO scores of public school applicants to the right so that the peaks of public and private school applicant distributions align. In the absence of any behavioural response from applicants, this shift should lead to a sizable increase in the share of public high school graduates among UNICAMP students. Using 2004 data to compute a counterfactual suggests that the bonus will change admission (first-round) offers for 247 applicants, representing $8.4 \%$ of the 2,934 available places. As shown below in Section 5, this is very close to the actual impact of the policy in 2005 measured by the number of applicants affected.

\subsection{Other Policies}

The timing of UNICAMP's policy implementation allows us to perform a short run analysis with minimal risk of confounders. Our analysis focuses on UNICAMP 2004 and 2005 admission exams. Registration for 2005 admission exam took place in September 2004, $P_{1}$ in November 2004, $P_{2}$ in January 2005, and successful candidates started classes at UNICAMP in February 2005. Therefore, our results based on 2004-2005 should not be affected by other policies that were implemented from 2005 onward.

UNICAMP was the only university in the state of Sao Paulo with an affirmative action policy until 2007 and one of the few universities in Brazil to implement such a policy before 2005. ${ }^{12}$ The risk of contagion effects from other states is minimal because student mobility in Brazil was very low. All other universities with affirmative action programs in 2005 or before were far from UNICAMP, with the closest one, UERJ, 500km from UNICAMP. Since each university had its own, distinct entrance exam, the cost of applying to universities in other states was significant. Moreover, incentives were low, as UNICAMP enjoyed a better reputation than most universities in the country. According to the 2000 Brazilian Population Census only $0.91 \%$ of individuals aged 20 to 24 were either working or studying out-of-state. Among UNICAMP applicants, only $12.3 \%$ were from out of state, and only $4.6 \%$ resided in a state that implemented an affirmative action policy before 2005 .

As public universities are free of charge and have good reputations across the country, private universities are typically seen as a last resort for applicants. UNICAMP's main competitors are the Universidade do Sao Paulo (USP) and the Universidade Estadual Paulista

\footnotetext{
${ }^{12}$ Affirmative action policies became widespread in Brazil after 2012, with the implementation of the federal law Lei de Cotas. Few Brazilian universities adopted quota systems in 2005 or before: in 2002, Universidade Estadual do Rio Grande do Sul (UERGS); in 2003, the Universidade do Estado do Rio de Janeiro (UERJ) and the Universidade Estadual do Norte Fluminense (UENF), the Universidade do Estado da Bahia (UNEB); in 2004, Universidade de Brasilia, Universidade Federal do Rio Grande do Norte (UFRN) e Universidade Estadual de Maringa (UEM).
} 
"Julio de Mesquita Filho" (UNESP), which implemented affirmative action policies only in 2007 and 2014, respectively. Most of the expansion of public universities in the state of Sao Paulo occurred after UNICAMP 2005 with the Universidade Federal do ABC (UFABC) in July 2005 and with the Universidade Federal de Sao Paulo (UNIFESP) in 2006. USP did increase its course offering in the 2005 entrance exam with the creation of Escola de Artes, Ciencias e Humanidades da USP (EACH/USP). The courses offered at the EACH/USP campus were mostly vocational courses, limiting the potential for confounding effects.

Around the time UNICAMP introduced its affirmative action policy two other programs were in place providing funding to attend private universities: ProUni, a scholarship program targeting high-achieving individuals was implemented in 2005 and Fies, a loan program for private university students, started in 1999. While the number of loans granted varies over the years, no major change occurred until 2010, when the program expanded considerably, and interest rates subsidies increased significantly. ${ }^{13}$

Thus, while the Brazilian higher education system underwent several changes over the last decades, none of them could have had a relevant impact on the application behaviour of UNICAMP 2004 and 2005 entrance exams. They could, however, affect the analysis of longerterm effects (beyond 2005) of the policy change, which therefore needs to be interpreted with a degree of caution.

\section{Theoretical Pointers}

Economic theory suggests that the affirmative action policy put in place by UNICAMP will induce substantial behavioural responses, in particular regarding the choice of exampreparation effort. Behavioral responses may well depend both on individual ability and, of course, on whether an individual stands to be favoured by the policy or not. To guide our empirical work, we draw on the literature on university admission following human capital investments, and use the model in Bodoh-Creed and Hickman (2016) to develop a numerical example of possible heterogeneous policy effects.

Let an economy be populated by a continuum of university applicants with measure 1 . Mass $\mu$ of applicants have minority background and $1-\mu$ are from the majority group. An

\footnotetext{
${ }^{13}$ See McCowan (2007) for a description of ProUni and Fies and a brief description of the Brazilian higher education system. ProUni was initially implemented through an executive order in September 2004 but converted into law in January 2005. The timing of ProUni makes it unlikely to affect the application to UNICAMP 2005 entrance exam. Indeed, the list of private universities joining ProUni was only known in November 2004, after UNICAMP $2005 P_{1}$ took place, and applicants started registering for ProUni in December 2004, shortly before $P_{2}$ took place. It is also unlikely that UNICAMP applicants would give up the entrance exam because of ProUni. As mentioned before, private universities typically enjoy lower reputation and are seen as last resort for most applicants.
} 
applicant $i$ is characterised by an ability type $\theta_{i}$ and the group she belongs to (minority or majority). She invests in exam-preparation effort $s_{i}$ at a utility cost of $C\left(s_{i}, \theta_{i}\right)=\frac{s_{i}^{2}}{2 \theta_{i}}$. That is, higher ability $\theta_{i}$ is associated with a lower marginal cost of effort. An applicant derives utility $U\left(P\left(s_{i}, s_{-i}\right), s_{i}\right)$ that depends on own effort $s_{i}$ and the probability $P\left(s_{i}, s_{-i}\right)$ of being admitted to university given her own and other applicants' effort choices $s_{i}$ and $s_{-i}$. Hence, an applicant's payoff depends both on her preparation effort and, through the admission probability, the competition she faces. Letting the payoff also depend positively on ability $\theta_{i}$, complementary to the other inputs, only marginally changes our simulation results below.

Suppose that an applicant is admitted through an entrance exam and the test score on the exam is a normally distributed random variable $g\left(s_{i}\right)$ with mean $s_{i}$ (the applicant's preparation effort) and variance $\sigma^{2}$. The university has capacity $\kappa$, so that (invoking a law of large numbers) applicants' choices $s_{i}$ pin down the distribution of $g\left(s_{i}\right), F\left(g\left(s_{i}\right)\right)$. Then there is $g^{*}$ such that $F\left(g^{*}\right)=1-\kappa$ and all applicants with $g\left(s_{i}\right) \geq g^{*}$ are admitted. Hence, an applicant $i$ is admitted with probability:

$$
P\left(s_{i}, s_{-i}\right)=1-\Phi\left(\left(g^{*}-s_{i}\right) / \sigma\right)
$$

where $\Phi($.$) denotes the standard normal distribution function. The cutoff grade g^{*}$ depends on the aggregate of applicants' effort choices, but - because of the continuum - not on applicant $i$ 's choice $s_{i}$.

In line with the assumptions in Bodoh-Creed and Hickman (2016), we choose the following functional form for our numerical simulation:

$$
U\left(P\left(s_{i}, s_{-i}\right), s_{i}\right)=s_{i}^{\alpha}\left(1-\Phi\left(\left(g^{*}-s_{i}\right) / \sigma\right)\right)
$$

where $\alpha \in[0,1]$. This formulation is chosen for simplicity and tractability but is robust to various changes in the model assumption. ${ }^{14}$ It reflects an applicant's expected benefit from entering university, which is simply her preparation effort $s_{i}$, weighted by a parameter $\alpha$, multiplied by the probability of gaining access to the university given own effort $s_{i}$ and the cutoff grade $g^{*}$ resulting from aggregate effort choice. Bodoh-Creed and Hickman (2016) show the existence of an equilibrium that is monotone in types in a general continuous setting, and that it approximates well the finite case.

The necessary condition for individuals' optimal effort choice $s_{i}^{*}$ is given by:

$$
\frac{s_{i}}{\theta_{i}}=\alpha s_{i}^{* \alpha-1}\left(1-\Phi\left(\left(g^{*}-s_{i}^{*}\right) / \sigma\right)\right)+s_{i}^{* \alpha} \frac{1}{\sigma} \phi\left(\left(g^{*}-s_{i}^{*}\right) / \sigma\right) .
$$

\footnotetext{
${ }^{14}$ Examples are to include $\theta_{i}$ into $U($.$) , and different parameterisations of the grade and type distributions.$
} 
The first term on the RHS of this expression reflects the investment aspect of preparation effort (a higher admission probability makes effort investment more productive), while the second term reflects its competitive effect (higher effort increases the probability to obtain benefits from university).

An admission policy that awards a bonus $b$ to the test score of minority applicants changes the admission probability to $1-\Phi\left(\left(g^{*}-s_{i}-b\right) / \sigma\right)$. This has a threefold effect on the equilibrium outcome: (i) the effort investment of minority applicants becomes more productive, for any given effort $s_{i}$, because the admission probability has increased, (ii) the marginal increase in the admission probability increases (decreases) for low (high) effort choices, and (iii) the cutoff test score $g^{*}$ changes. Only (i) has an unambiguous sign, but the general effect will depend on whether an applicant receives a bonus or not, and that applicant's rank in the ability distribution.

Because of its timing, the bonus-point system implemented in UNICAMP can be expected to have primarily affected exam-preparation. Preparation and revising for the university entrance exam, i.e., cramming, is not likely to increase human capital meaningfully (unlike, e.g., ten years of schooling). Thus preparation effort will not by itself affect a student's benefit from attending university. Therefore we set $\alpha=0$, i.e., preparation effort for the entrance exam does not make a student more productive in university, given the student's human capital from high school. Then only the second term on the RHS of equation (2) remains. This poses a fixed point problem of finding a cutoff grade $g^{*}$, such that optimal effort levels $s_{i}^{*}$ given $g^{*}$ yield exactly $g^{*}$ as a cutoff grade, given stochastic grades $g\left(s_{i}^{*}\right)$. This fixed point problem can be solved numerically.

To gain some guidance for the possible behavioural effects and to solve the model numerically, we let the ability parameters $\theta_{i}$ be normally distributed with mean 0.5 and standard deviation 0.25 for both minority and majority applicants. We fix the population shares at 0.75 for the majority and 0.25 for the minority in line with the data and set $\sigma=0.35$ for the normally distributed grades $g($.$) . The bonus for minority applicants is set to 0.1$ (reflecting a bonus of approximately $30 \%$ of a standard deviation in the data). Computing the resulting equilibrium behaviour yields Figure 2 .

[ Figure 2 approximately here. ]

Figure 2 depicts the change in effort level as a function of the applicant's ability $\theta_{i}$ when the university moves from a laissez-faire situation to a bonus-points admission policy. These changes differ between applicants not receiving the bonus (majority applicants) and those who do (minority applicants). On average, applicants receiving the bonus increase their effort 
by 0.019 , which can be interpreted as 0.019 entrance grade points. The remaining applicants decrease their effort by 0.035 (grade points). The cutoff grade to enter the university is 0.675 . The modest average effects mask considerable heterogeneity: minority (majority) applicants with lower ability will increase (decrease) their effort, while those with higher ability will decrease (increase) their effort compared to laissez-faire.

The vertical lines in Figure 2 indicate the cutoff ability types; $\theta_{\min }\left(\theta_{\text {maj }}\right)$ denote the minority (majority) ability type that chooses equilibrium effort such that the expected grade including a bonus is just equal to the cutoff grade. Since effort determines expected grade and strictly increases in ability type, the pattern in Figure 2 carries over from the ability to the grade distribution. This yields some predictions that we can test using the change in the performance gap between public and private high school applicants. First, on average, we expect that the admission-exam performance of public high school applicants will improve relative to their private high school counterparts, following the introduction of the affirmative action. Second, we expect the change in the public-private performance gap to vary significantly across the $\theta$ distribution. Most of the action should occur close to the cutoffs, while very high and very low ability types should be less responsive to the policy change. If $\theta$ is well approximated by the applicants' ENEM scores, one would not expect to observe a significant change in the private-public performance gap for applicants at the bottom of the ENEM distribution. The performance gap should shrink the most for applicants around the second quartile (from the bottom) of the ENEM distribution, and it should worsen for applicants at the top of the ENEM distribution. Moreover, the simulation suggests that responses to the policy will have different signs for applicants above and below the cutoff types, conditional on receiving the bonus or not.

It is noteworthy that the pattern of policy effects depending on academic ability remains stable over a range of different parameterisations. However, the magnitude of the implied effects varies with parameters such as the variance of the grade, the distribution type, and the effort cost function. In particular, the latter plays an important role, as it determines the elasticity of effort choice with respect to cost type and thus the implied change of effort stemming from a bonus policy. Using a more convex cost function reduces the elasticity of effort in equilibrium and thus the magnitude of the expected effect. For example, $C\left(s_{i}, \theta_{i}\right)=$ $\frac{s_{i}^{4}}{4 \theta_{i}}$ would reduce the predicted magnitude of the effect shown in Figure 2 by about two thirds. That is, whether the behavioural responses to the policy implied by the model are large enough to be relevant for the policymaker is an empirical question. 


\section{$3 \quad$ Data and Descriptive Statistics}

Our main data source is a rich administrative dataset provided by UNICAMP. This dataset contains information on all applicants who registered for UNICAMP's entrance exam (vestibular) in the years 2003 to 2008. Every year more than 40,000 applicants register for UNICAMP's admission exam. Our dataset contains background information for each applicant, in particular, gender, age, race (i.e., Asian, black, mulatto, native, or white) and whether they attended a public secondary school. Importantly, the data also include information on the applicant's family characteristics such as her family income, and both of her parents' education levels and occupations. Our data allow us to observe everything that happens during the admission exam: for each applicant, we observe their performance in each part of the exam they participated in and whether they were admitted and enrolled at UNICAMP (and their major, once enrolled).

Importantly, we observe the applicants' ENEM scores, which will serve as our main control for the applicants' academic ability. The ENEM score is available for all applicants who permitted to UNICAMP to obtain this information from the Ministry of Education. Since an applicant's ENEM score cannot decrease her $P_{1}$ score, she has no incentives for denying permission. The percentage of our sample reporting ENEM is very large (around 90\%) and has been remarkably stable over the years. ENEM raw scores are not directly comparable across years, even though there were no significant changes in the exam formulation until 2008. To make scores comparable we normalise ENEM scores such that every year the ENEM score distribution of all ENEM takers in the state of Sao Paulo has a mean of 0 and a variance of 1 . Similarly, both $P_{1}$ and $P_{2}$ scores are normalised such that every year they have a mean of 0 and a standard deviation of 1 .

We make a series of restrictions to focus on our population of interest. First, we discard applicants who do not take the exam for immediate admission (i.e. the trainees who take the exam as a practice test) and applicants who registered but did not write the exam. ${ }^{15}$ These two groups represent 4.5 and 4.2 of the original 2004-2005 sample, respectively. We drop applicants who did not do their secondary education in Brazil (0.7\% of the original population). We discard applicants for whom important information is missing (i.e. missing gender, age, the type of secondary school attended, affirmative-action information, or parental education), which eliminates $7.0 \%$ of the initial population. Finally, we drop applicants who

\footnotetext{
${ }^{15}$ Some students who take the vestibular do not plan to join the university: some students who will not finish high school in time for enrollment register for the exam as "trainees" (treineiros)-they write the exam as a practice test. We exclude these individuals from most of our analysis. We use them to investigate a change in absolute effort level (from both private and public high school applicants) following the introduction of the affirmative action (see Section 5).
} 
did not report their ENEM score, which reduces the sample by 8.7\%. For 2004 and 2005, the final sample contains 38,756 and 39,457 observations, respectively. ${ }^{16}$

Information on the distributions of private and public high school leavers comes from the Brazilian School Census. The School Census data are collected every March and cover the universe of all public and private schools in Brazil. We focus on the School Census data for the state of Sao Paulo, which is where the vast majority of applicants comes from.

Finally, we use aggregate (public) data from USP entrance exam available on the FUVEST website (www.fuvest.br). The data are available by major and contain the frequencies of responses to the socioeconomic survey filed by all USP candidates, a survey similar to the one from which we obtained UNICAMP applicants' background data. We use data on the type of secondary school (i.e., public or private) and race to compare the pool of applicants and enrollees at both institutions. We drop the data on EACH/USP, the new campus created in 2005, to avoid confounders that could mislead our interpretations of the trends at USP. We use aggregate data on all majors (except EACH/USP) and also for a sample that restricts the data to majors that are most similar at USP and UNICAMP.

[ Tables 1 and 2 approximately here. ]

Tables 1 and 2 compare the applicant pools before and after the intervention (columns (1) and (2)). One year after the policy change applicants were more likely to come from a public school and to belong to a visible minority, have higher parental education, but were less likely to have previously attended university, or an exam-preparation course. The increase in public school applicants appears to have been short-lived, however: by 2008 it had returned to pre-affirmative action levels (close to 30\%) at UNICAMP, as shown in Table 2. In columns (3) and (4), we restrict the sample to $P_{1}$ survivors, which appear as a much more similar group in 2004 and 2005, as compared to the entire applicant pool. The share of minority applicants among stage $P_{1}$ survivors, in particular from public high schools, has increased, but not the share of public school alumni. While the educational composition of the applicant pools change, with more applicants having university-educated parents, the over-representation of applicants with university-educated parents among stage $P_{1}$ survivors does not appear to change markedly in 2005. Survivors' normalised ENEM scores increased after the intervention, indicating that competition for places has become substantially stiffer after the intervention.

[ Figures 3 and 4 approximately here. ]

\footnotetext{
${ }^{16}$ We impose the same restrictions for 2003-2008 and obtain very similar reductions in sample size.
} 
Figure 3 suggests that cohort effects and general time trends may have generated the socioeconomic-characteristic patterns observed in Tables 1 and 2. Indeed, USP, UNICAMP's closest competitor, experienced a similar increase in public school and visible minority applicants. Figure 4, which compares UNICAMP's applicants to high school graduates in the state of Sao Paulo, suggests that a cohort effect can partially explain the surge: both graduate numbers and the proportion of public high school students among these graduates increased in 2005. As discussed in Section 1, we cannot exclude that other policies, such as ProUni, affected the applicant pool beyond 2005.

Time trends can explain most other differences as well, as shown in Figure 5. The time series of several attributes of $P_{1}$ survivors look remarkably stationary, with the possible exception of visible minorities (which were self-declared), and the mean ENEM score. The increase in visible-minority applicants was short-lived: the share of visible minorities plateaued after 2005 for both public and private high school applicants. The evolution of ENEM scores follows no particular trend, but is similar for public and private school applicants.

[ Figure 5 approximately here. ]

Thus, we cannot exclude that the policy altered the composition of UNICAMP applicants, although the changes are small and seem to relate at least partially to time trends. However, $P_{1}$ survivors are very similar in 2004 and 2005, a fact that our identification strategy will exploit.

\section{Econometric Approach}

Our analysis has two main objectives. First, to assess the overall policy outcome, i.e., whether and how the affirmative action policy has redistributed access to higher education at UNICAMP, and second, to examine whether the redistribution was hampered or helped by behavioural responses on the exam-preparation effort.

\subsection{Overall Outcome and Redistribution}

For our first objective, we use a difference-in-difference framework. Denote the outcome by $A_{i, c, m, t}$, a binary variable equal to one if the applicant $i$ from municipality $m$ and applying to major $c$ in year $t$ was admitted, and zero otherwise. We focus on admission rather than enrollment, because the aim of the policy was to ensure equal opportunities rather than equal outcomes (results for enrollment are similar, however). In our most basic specification we regress $A_{i, c, m, t}$ on a series of binary variables indicating: whether the applicant is from a 
visible minority, $V_{i}$, went to a public secondary school, $P_{i}$, was observed during UNICAMP's affirmative-action years, $A A_{t}$, as well as their interaction terms. The interaction terms involving $A A_{t}$ are our variables of interest. $P_{i} \times A A_{t}$ captures the change in admission probability (following the affirmative action policy) for non-minority applicants from public high schools, relative to their private school counterparts.

We augment our base specification to control for the applicant's characteristics (i.e., gender, a quartic function of age, parental educational attainment, an indicator variable for previous university attendance), $\boldsymbol{X}_{\boldsymbol{i}}$, as well as for municipality, major choice, and year fixed effects $\left(\mu_{m}+\eta_{c}+\tau_{t}\right)$. Importantly, we control for the applicant's academic ability using our normalised ENEM measure. Hence, in the specifications, in which we control for $E N E M_{i}$, we will measure changes in admission probability conditional on student ability. Simultaneously controlling for year and major fixed effects, as well as $E N E M_{i}$, will take into account the possibility that the link between $E N E M_{i}$ and the admission probability changed (but similarly for everyone) following the policy change and that some majors are more competitive than others. Finally, by including municipality fixed effects, we also control for potential state-level differences (e.g. high school quality) that could affect applicants. The main regression equation is given by:

$$
\begin{aligned}
A_{i, c, m, t}= & \alpha P_{i}+\delta V_{i}+\pi\left(P_{i} \times V_{i}\right)+\rho\left(P_{i} \times A A_{t}\right)+\beta\left(V_{i} \times A A_{t}\right)+\gamma\left(P_{i} \times V_{i} \times A A_{t}\right) \\
& +\phi E N E M_{i}+\boldsymbol{X}_{\boldsymbol{i}} \boldsymbol{\Gamma}+\mu_{m}+\eta_{c}+\tau_{t}+\varepsilon_{i, c, m, t},
\end{aligned}
$$

where $\varepsilon_{i, c, m, t}$ represents the error term. We allow our error terms to be two-way clustered, at the major and municipality levels (see, e.g., Cameron et al., 2011; Cameron and Miller, 2015). This is to account for the potential correlation in error terms for applicants with similar major choice and from the same geographical region (who may well have experienced similar shocks in their prior education). Moreover, allowing for clustering at the major and municipality levels takes into account some of the serial-correlation issues related to difference-in-differences estimation raised by Bertrand et al. (2004). We will use this regression framework to examine whether before the policy private school applicants indeed had an advantage over public school applicants in being admitted, controlling for a host of observable covariates and whether the policy reduced potential differences in admission probabilities between private and public school applicants. ${ }^{17}$

To investigate the potential redistributive effect of the affirmative action policy along socio-economic dimensions we perform a similar exercise to the one in Bertrand et al. (2010).

\footnotetext{
${ }^{17}$ Descriptive evidence presented in Tessler (2006), Kleinke (2006), and Pedrosa et al. (2007) suggests that the policy was successful in increasing participation of targeted groups.
} 
That is, we compare the characteristics of displacing and displaced applicants. Displacing applicants are those who would not have gained admission without the policy (the 30- or 40-point bonus), given the distribution of entrance exam scores, and the displaced are those applicants who would have gained admission in the absence of the policy but did not under the policy. This approach allows us to shed light on whether any redistribution of offers was from higher to lower socio-economic status (SES) students, as conjectured, and whether the redistribution came at the cost of academic ability of admitted students.

\subsection{Behavioral Response}

The theory presented in Section 2 suggests that any measured effect on admission is generated by pure redistribution as well as by applicants' behavioural responses to the new rules. We now describe our strategy to assess whether behavioural responses in the exam-preparation effort amplified or dampened the policy's redistribution of access to higher education.

Since we do not observe effort directly, we measure effort by the difference between applicants' actual entrance exam score and their predicted exam scores in $P_{2}$ given their characteristics (i.e., their ability, as measured by their ENEM score, and other control variables used in regressions). ${ }^{18}$ The crucial assumption allowing for identification of the effort differential is that the link between applicant's ability and the ENEM score (and therefore the link between the ENEM score and UNICAMP's admission exam performance) did not change differently over time for public and private high school graduates. This assumption will be satisfied if the introduction of the affirmative action did not affect students' ENEM exams, which is true for the cohort applying in 2005 at UNICAMP, given the timing of the policy. For later years the necessary assumption is that if the introduction of the affirmative action policy distorted the link between academic ability and the ENEM score, then it did so in the same way for all applicants.

The roll-out of the policy in 2005 did not leave applicants with enough time to adjust their preparation for the ENEM exam, but did give applicants ample opportunity to react in their preparation for both stages of the admission exam. Registration for UNICAMP's 2005 admission exam opened on August 30, 2004 and lasted for one month. The main source of information regarding the affirmative action policy was the applicant's manual (COMVEST, 2005), which candidates had access upon registration, and the online registration form, which explicitly required applicants to opt or not for the affirmative action policy. The manual was published on August 27, 2004, while the 2004 ENEM exam (i.e., the latest ENEM score that could be used for UNICAMP's 2005 admission exam) took place on August 29, 2004.

\footnotetext{
${ }^{18}$ Morin (2015) uses a similar approach to investigating the effect of increased competition on university performance.
} 
Hence, individuals had at most two days to adjust their preparation for the ENEM exam, which is unlikely to have had any discernible effect. UNICAMP's $2005 P_{1}$ exam took place on November 21, 2004, and $P_{2}$ in mid-January 2005, giving applicants about 3 and 4.5 months, respectively, to adapt their preparation effort for the admission exams in reaction to the policy announcement. Therefore, we will interpret a change in the public-private performance gap (conditioning on ability) following the introduction of the affirmative action as evidence of a change in the public-private effort gap.

We use the regression framework presented in equation (1), replacing the dependent variable $A_{i, c, m, t}$ with the normalised exam score $S_{i, c, m, t}$ of applicant $i$ from municipality $m$ who applies to major $c$ in year $t$ as a dependent variable. The only difference regarding control variables is that we control for the ENEM score in all specifications. The coefficients of interest (associated with the interaction with the dummy variable $A A_{t}$ ) will then reflect the policy's effect on the performance of applicants from public schools and visible minorities relative to their majority private school counterparts.

There is, of course, a possibility of selection on observables and unobservables into or out of applying to UNICAMP as a consequence of the policy. Although our data suggest little change in the applicant pool in 2005, see Section 3, we employ two strategies to deal with possible selection on observables and unobservables. The first is straightforward, namely to control for a host of observables when using the difference-in-difference approach described above. This strategy will reduce selection bias to the extent that the unobservables are correlated with our control variables. Our second strategy exploits the unique nature of the data: recall that the entrance exam consisted of two parts, $P_{1}$ and $P_{2}$, and that only applicants who passed $P_{1}$ were admitted to $P_{2}$. The design of affirmative action policy is such that eligible applicants receive the bonus points only in $P_{2}$ of the admission exam (i.e., only eligible $P_{1}$ survivors can get the bonus). The two parts of the entrance exam were designed not to differ over time. Therefore the event of having passed $P_{1}$ effectively controls for unobserved heterogeneity in academic ability as, in every year, before and after the policy change, only individuals who passed $P_{1}$ were admitted to $P_{2}$. In other words, the distribution of $P_{1}$ stage survivors is a truncation of the applicant distribution, truncated at the same (unobserved) ability level every year. We run our regression for the full sample of $P_{1}$ stage survivors but also split our sample into ENEM quartiles to account for possible heterogeneous effects, as predicted by the theoretical framework. Both approaches will capture the average effect, either in the full sample or the subsamples defined by ENEM quartiles.

One might argue that average effects could mask significant heterogeneity of behavioural responses. For instance, as suggested in Section 2, not only may the individual response in effort provision to receiving a bonus or not depend on the individual's rank in the ability 
distribution, but also may applicants below and above the cutoff react differently. A particular complication is that, given that each major has its own cutoff, subsamples formed by ENEM quartiles contain simultaneously individuals above and below the cutoff who could react differently to the policy.

To account for this possibility, we construct a "predicted distance to cutoff", Dist $t_{i, c, m, t}$, for each individual who applied in 2004 or 2005 . We use the applicants who passed $P_{1}$ in 2004 to estimate a regression of their $P_{2}$ performance $\left(N P O_{i, c, m, t}\right)$ on the same regressors as in equation (1) (except for the ones involving time) and predict the 2004 and 2005 scores using the estimated coefficients from this regression:

$N \widehat{P O_{i, c, m, t}}=\hat{\kappa}_{1,04} P_{i}+\hat{\kappa}_{2,04} V_{i}+\hat{\kappa}_{3,04}\left(P_{i} \times V_{i}\right)+\hat{\kappa}_{4,04} E N E M_{i}+\mathbf{X}_{\mathbf{i}} \hat{\Theta_{04}}+\hat{\mu_{m, 04}}+\hat{\eta_{c, 04}}+\hat{\tau_{04}}$.

We base both 2004 and 2005 predicted scores on the 2004 regression results to avoid contamination by the introduction of the affirmative action policy. The applicant's predicted score is compared to the previous year's cutoff, given the major applied to. This cutoff is available every year in the applicant's manual and corresponds to the score of the last admitted applicant (i.e., the admitted applicant with the lowest P2 score) in each specific major. The idea is that applicants should have an idea of how close they are from last year's cutoff given their characteristics. The predicted distance to cutoff, Dist $t_{i}$, is normalised using the standard deviations of these distances (computed for every major-choice/year combination):

$$
\operatorname{Dist}_{i, c, m, t}=\frac{\text { cutof } f_{c, t-1}-N \widehat{P O_{i, c, m, t}}}{\operatorname{s.d.}\left(\widehat{N P O_{c, t}}\right)}
$$

Note that each regression specification has its own vector of predicted-distance-to-cutoff values given that the predicted scores are computed using different sets of regressors.

Applying the bonus points to the predicted-distance-to-cutoff of those favored by the policy puts us in a position to predict whether an applicant will be below or above the cutoff. We construct a binary variable, Above $_{i}$, accordingly:

$$
\text { Above }_{i, c, m, t}= \begin{cases}1 & \text { cutof } f_{c, t-1}-N \widehat{P O_{i, c, m, t}}-30\left(P_{i} \times A A_{t}\right)-10\left(P_{i} \times V_{i} \times A A_{t}\right) \leq 0 \\ 0 & \text { otherwise. }\end{cases}
$$

The computation of these predicted distances to cutoffs is conceptually the same as deriving the distance to the majority-applicant cutoff in Figure 2. The affirmative action bonus points are equivalent to decreasing the distance to the cutoff for applicants favoured by the policy. Figure 2 predicts that private and public applicants at the same distance of the majority cutoff $\left(\theta_{m a j}\right)$ will react differently to the affirmative action and that this difference in reaction should also depend on whether the candidate is expected to be above or below 
the cutoff. Therefore, we will test these predictions by interacting our distance measures $\left(\right.$ Dist $_{i, c, m, t}$ and Above $\left._{i, c, m, t}\right)$ to our regressors of interest (e.g. $P_{i} \times A A_{t}$ ). Our regression equation then becomes:

$$
\begin{aligned}
& S_{i, c, t, t}=\beta_{1} P_{i}+\beta_{2} V_{i}+\beta_{3}\left(P_{i} \times V_{i}\right)+\beta_{4}\left(P_{i} \times A A_{t}\right)+\beta_{5}\left(V_{i} \times A A_{t}\right)+\beta_{6}\left(P_{i} \times V_{i} \times A A_{t}\right) \\
& +\operatorname{Dist}_{i, m, t}\left(\alpha_{0}+\alpha_{1} P_{i}+\alpha_{2} V_{i}+\alpha_{3}\left(P_{i} \times V_{i}\right)+\alpha_{4} A A_{t}+\alpha_{5}\left(P_{i} \times A A_{t}\right)+\alpha_{6}\left(V_{i} \times A A_{t}\right)+\alpha_{7}\left(P_{i} \times V_{i} \times A A_{t}\right)\right) \\
& + \text { Above }_{i, m, t}\left(\pi_{0}+\pi_{1} P_{i}+\pi_{2} V_{i}+\pi_{3}\left(P_{i} \times V_{i}\right)+\pi_{4} A A_{t}+\pi_{5}\left(P_{i} \times A A_{t}\right)+\pi_{6}\left(V_{i} \times A A_{t}\right)+\pi_{7}\left(P_{i} \times V_{i} \times A A_{t}\right)\right) \\
& + \text { Above }_{i, c_{m, t}} \times \operatorname{Dist}_{i, G, t, t}\left(\gamma_{0}+\gamma_{1} P_{i}+\gamma_{2} V_{i}+\gamma_{3}\left(P_{i} \times V_{i}\right)+\gamma_{4} A A_{t}+\gamma_{5}\left(P_{i} \times A A_{t}\right)+\gamma_{6}\left(V_{i} \times A A_{t}\right)\right. \\
& \left.+\gamma_{7}\left(P_{i} \times V_{i} \times A A_{t}\right)\right)+\phi E N E M_{i}+\boldsymbol{X}_{i} \boldsymbol{\Gamma}+\mu_{m}+\eta_{c}+\tau_{t}+\varepsilon_{i, c, m, t} .
\end{aligned}
$$

This specification essentially allows the slope and the intercepts of the curves depicted in Figure 2 to differ based on the applicant's distance to the cutoff, on whether they are expected to be above or below the cutoff, and on whether they receive a bonus or not. For example, $\alpha_{5}$ will capture changes in the slope differential between public and private (white) applicants (i.e. the slope of the red curve relative to the slope of the blue curve in Figure 2) as one gets closer to the cutoff (from below). Similarly, $\pi_{4}+\pi_{5}$ will capture the intercept difference (in Figure 2), between public applicants above and below the cutoff.

To take into account that we are using generated regressors, the standard errors are computed using 500 block-bootstrap replications (at the major level). In each replication we compute new sets of expected distances to cutoff and the regressions of interest.

\section{$5 \quad$ Main Results}

\subsection{Individual Admission Probabilities}

We investigate the overall admission impact of the affirmative action policy by analysing changes in the admission probability of the different groups. Table 3 presents the results of estimating equation (1) for the years 2004 and 2005. Specifications (1) to (5) use an increasing set of control variables to assess the robustness of our findings.

[ Table 3 approximately here. ]

We start by examining the public-private admissions gap before the affirmative action policy was introduced (i.e., coefficient $\alpha$ in equation (1)). While Specifications (1) and (2) show that public high school applicants indeed had worse admission prospects, Specification (3) seems to suggest the opposite: controlling for academic ability yields a significantly higher admission probability for public school applicants and no difference for visible minorities. Notice that the results also suggest that ENEM score is a good proxy for academic ability 
because its coefficient estimate is highly significant: a one-standard-deviation difference in ENEM score is associated with a 12.4 percentage point difference in admission probability. Specification (4), however, shows that the apparent advantage of public high school applicants is due to selection on observables, specifically on the major chosen. When we control for major fixed effects, the public high school coefficient estimate reverts to the expected negative sign, suggesting that public school applicants choose less competitive majors than their private school counterparts. Using our full set of controls in Specification (5) results in a sizable difference in admission rates: the private-public high school difference is 1.4 percentage points. This difference is substantial, given an overall admission rate of $10.5 \%$ in 2004 (see Table 1), and supports the public perception of an admission disadvantage for public school applicants.

The introduction of the affirmative action policy is associated with an increase in admission probabilities for public school applicants. Focusing on Specification (5), the privatepublic difference decreased by 2.8 percentage points for white applicants and thus became a 1.4 percentage-point advantage for public school applicants under the affirmative action policy (although the p-value from testing the null hypothesis $H_{0}: \alpha+\rho=0$ is 0.0914 ). In contrast, the white-minority gap increased significantly, by 1.6 percentage points, for applicants from private schools (a gap that was essentially zero before the affirmative action).

Despite the fact that visible minority applicants from public schools receive an additional 10 points (on top of the 30 points received by all public high school graduates), the change in admission probability for these applicants is similar to that of white public school applicants $(\beta+\gamma$ is not statistically different from zero at conventional confidence levels). However, we cannot exclude that this result is due to changes in composition, which seemed to have particularly affected the minority group at public schools.

To sum up, the policy led to a substantial increase in admission probability for applicants from public schools. The main losers from the policy were visible minority applicants from private schools, as they experienced a decrease in admission probabilities. Extending the period of analysis to the years 2003-2008 does not change our results meaningfully (see Table 4), even though we cannot exclude that the longer run sample is affected by other policies, as discussed in Section 1.

[ Table 4 approximately here. ]

\subsection{Redistribution along Socio-economic Characteristics}

We now examine the possible redistributive effect of the affirmative action policy along socioeconomic dimensions by comparing the characteristics of displacing and displaced applicants. 
Given the distribution of entrance exam scores in 2005, there are 268 applicants who would not have been admitted in the first round without the bonus points awarded by the policy (the displacing, reassuringly almost all are from public schools), and correspondingly 268 applicants (the displaced, the great majority from private schools) who would have gained admission had the applicants from public school not been awarded their bonus. ${ }^{19}$ This number represents $9.1 \%$ of the 2,934 available places, and $38.7 \%$ of 692 candidates admitted in the first round that received the bonus $-61.3 \%$ of them would have been admitted even without the bonus points.

Table 5 depicts the characteristics of the displacing and displaced applicants. First, displacing applicants are more likely to belong to a visible minority and to come from a more disadvantaged background, reflected by parental education, occupation, and income. ${ }^{20}$ For instance, while $53 \%$ of displaced candidates' mothers have a university degree, this number halves to $25 \%$ for the displacing group. Similarly, nearly $55 \%$ of displaced candidates' fathers had a medium-to-top or top occupation, while the corresponding number among the displacing group is only $23 \%$. Indeed, all variables associated with parental education and occupation, as well as to financial constraints show significant differences. Hence, the policy seems to have been successful in broadening access to UNICAMP to applicants from disadvantaged backgrounds, in line with the results obtained by Bertrand et al. (2010) in India. Second, and perhaps surprisingly, displacing and displaced applicants do not differ significantly in their ENEM scores. That is, if one accepts the ENEM score as a viable proxy for academic ability, the policy seems to have redistributed places at UNICAMP from advantaged to less disadvantaged socio-economic backgrounds without compromising admitted students' academic ability.

[ Table 5 approximately here. ]

\subsection{Exam-preparation Effort}

Turning to possible behavioural responses, we focus on the difference in the public-private performance gap conditional on ENEM scores. As explained in Section 4, our main identification strategy relies on the fact that $P_{1}$ provides us with a convenient filtration of the applicant pool in terms of exam performance. Indeed, Table 6 suggests that the policy

\footnotetext{
${ }^{19}$ Note that since the admission rules depends sequentially on first, second, and third choices of major, some of the displacing applicants may be from private schools, and some of the displaced may be from public schools. However, there were very few of those cases in 2005: three displacing were from private schools, and nine displaced were from public high schools.

${ }^{20} \mathrm{We}$ present the descriptive statistics for income, but do not include it in the regressions as control since this information tends to be affected by large measurement error. This is aggravated by the fact that applicants have to report on their parents' income.
} 
did not affect the probability of passing $P_{1}$, and hence to participate in $P_{2}$. The samples of 2004 and $2005 P_{1}$ survivors appear very similar with respect to a number of observable characteristics (see Section 3).

[ Table 6 approximately here. ]

Table 7 compares the change in relative $P_{2}$ performance of public and private high school applicants, following the introduction of the affirmative action policy. The results suggest minimal changes in the effort levels in response to the policy change. In particular, the bonus does not seem to have had any discernible encouragement or discouragement effects on the performance of public high school applicants relative to private high school applicants. Indeed, none of our parameter estimates of interest is statistically significant and all are very close to 0. Our findings are somewhat surprising as $P_{2}$ counts for at least $80 \%$ of the final admission score, and the bonus is quantitatively relevant. A similar exercise using $P_{1}$ scores gives very similar results. ${ }^{21}$

\section{[ Table 7 approximately here. ]}

Overall, we do not find significant results for the sample of $P_{1}$ survivors. Interestingly, examining $P_{2}$ scores separately by subject (examining ten subjects in total) yields that public school candidates improved their performance relative to private school applicants in mathematics and chemistry, and visible minorities from private schools (who did not get the bonus) performed worse in chemistry and history (results not shown here). The signs of these (statistically significant) coefficients correspond to the predictions of the theoretical framework. Therefore applicants may have reacted in a couple of subjects, but the reactions were not large enough to generate changes in overall relative performance.

The estimation strategy presented in Section 4 is designed to capture changes in relative performance between private and public high school applicants. It is possible that the 'absolute' performance of both groups changed in the same way (e.g., both may have improved similarly). In this case focusing only on the results in Table 7 would ignore a potentially important behavioural channel. To examine a possible common reaction of private and public high school applicants to the policy change we use a group of applicants whose effort and absolute performance are not likely to have changed following the policy. Every year roughly $4.5 \%$ of UNICAMP's admission exam takers register as 'treineiros' (trainees). Trainees take the exam as mere practice, since they do not graduate from high school in the current year, and do not compete for admission. Therefore they are not likely to have been affected by the

\footnotetext{
${ }^{21}$ These results are not presented here but available in a previous draft of this paper (Estevan et al., 2016).
} 
affirmative action policy. Trainees are thus a useful benchmark for whether the performance of private and public school applicants (who compete for admission) improved (or worsened) after the policy change.

We regress the 2004-2005 P2 test scores of trainees on dummy variables indicating whether they 1) come from a public high school, 2) are a visible minority, and 3) are observed in 2005 (i.e., "AA Years"), as well as on applicant personal characteristics (e.g., ENEM score, age, and parental education). ${ }^{22}$ Here the coefficient of interest is the one associated with the affirmative action year. This parameter will indicate whether the introduction of the affirmative action policy was associated with trainees improving relative to applicants competing for admission. Since P2 test scores are normalised using only applicants competing for admission, the coefficient captures trainee performance relative to other applicants. In particular, changes in test difficulty between 2004 and 2005 will be absorbed by this normalisation and will not affect our regression results. Thus, if trainees' preparation effort and absolute performance did not change after the policy change, a statistically significant parameter estimate for "AA Years" would suggest that applicants competing for admission did change their behaviour and performance.

Table 8 presents the results from the regressions described above. None of the estimates of the "AA Years" coefficient is statistically significant at conventional levels, and they are close to zero (particularly so for specifications where we include additional applicant controls). Ignoring statistical significance, the estimates would suggest that applicants competing for admission improved slightly following the introduction of the affirmative action. The results suggest that the overall performance of applicants potentially affected by the affirmative action (whether from private or public high schools) did not change significantly.

[ Table 8 approximately here. ]

Turning to potential heterogeneous effects by applicant ability, we start by splitting our sample into four quartiles based on the ENEM score and estimate separate regressions for each of them. Table 9 presents the results from the bottom (Q1) to the top (Q4) quartile. Only one parameter of interest is statistically significant: ${ }^{23}$ Focusing on the bottom quartile, public high school applicants improved relative to private high school white applicants. Observing such an effect in the lower half of the ENEM distribution is in line with the theoretical prediction, see Figure 2. However, one would expect the improvement to occur mainly in the second quartile.

\footnotetext{
${ }^{22}$ Given that there are only three trainees who are visible minorities, and from a public high school, we do not include a "Visible Minority $\times$ Public HS" dummy. Including this variable in our regressions does not change our estimates of interest.

${ }^{23}$ Since visible minorities from public high schools represent only five $\%$ of our sample, the number of observations by quartile for this group becomes quite small and the parameter estimates become imprecise.
} 
[ Table 9 approximately here. ]

The analysis by ENEM quartile cannot account for the possibility that individuals with lower ENEM scores apply to different majors than applicants with higher ENEM scores and hence could be closer to their respective cutoffs. Moreover, the change in performance observed for public high school applicants in the bottom quarter may not be large enough to affect their actual acceptance rate.

To shed some light on the potential heterogeneity in policy effects by individuals' position relative to the cutoff we turn to the theory. Figure 2 predicts that individuals (both private and public applicants) at the bottom of the ability distribution (very far from the cutoff) should not react to the policy. As ability increases (and the distance to the cutoff decreases), public high school applicants start increasing their effort level relative to their private high school counterparts up to the cutoff. Therefore, the difference in the slope (i.e. the Dist $_{i, c, m, t}$ coefficient difference) between these two groups should decrease in the distance to cutoff as a result of the policy change. One would expect the opposite to occur above the cutoff: moving away from the cutoff public the high school applicants may be tempted to slacken off because they are helped by the bonus. The opposite is true for their private school peers. Thus, the difference in the slope between public and private school applicants should increase in the distance above the cutoff after the policy change.

Table 10 presents the results from estimating equation (2), allowing applicants' reaction to differ in the location of their predicted score relative to the cutoff. ${ }^{24}$ The top panel of Table 10 summarises the changes in slope estimates, while the bottom panel presents the changes in performances above and below the cutoff, relative to white applicants who attended a private high school (detailed regression results are under Specification (5) of Table 11). The estimates related to visible minorities are very imprecise (especially for those from public schools) due to the small number of observations, and therefore we focus our analysis on white applicants from public and private high schools. Excluding visible minorities yields estimates for white applicants very similar to the ones presented here.

\section{[ Table 10 approximately here. ]}

The estimation results are much the same for individuals below or above the cutoff. The estimated changes in the slopes are not statistically significant, and they are small (given the distance to the cutoff is normalised such that for every year/major choice, the standard deviation is 1). The change in slope difference above the cutoff $-0.076(-0.094+0.018)$ is also

\footnotetext{
${ }^{24}$ Note that the number of observations decreases slightly $(3.3 \%)$ when estimating equation (2) since we have to drop observations in new majors, for which the previous year's cutoff (i.e., 2003) is not available.
} 
not statistically significant. Focusing on the sign of the estimates and ignoring the statistical significance, we note that the signs are generally not in line with the model predictions.

\section{[ Table 11 approximately here. ]}

Even though the slope differentials might not have changed significantly, it is still possible that individuals below and above the cutoff have reacted differently, as the intercepts for the distance to the cutoff might have changed. We investigate this possibility in the bottom panel of Table 10 where we look at changes in performance for our different groups of applicants following the policy. The values for distance to the cutoff used in computing the change in performance are 1.0 and -0.8 for individuals below and above the cutoff, respectively. These values represent the median distances for these two groups. The changes in relative performance are small and statistically nonsignificant, whether we look below or above the cutoff. Although we see a small increase in performance from white private high school students above the cutoff (something the model would predict), this increase is smaller than the one observed for their public high school applicants. Overall, we do not see strong evidence of heterogeneity in response to the affirmative action.

\section{General Equilibrium Effects}

Our results in Section 5 indicate a significant redistribution of admission offers from private to public school applicants. An important policy question is then whether the observed redistribution is a genuine expansion of access to selective universities for the underprivileged or whether it just reflects general equilibrium effects, i.e., public school applicants selecting into UNICAMP instead of similarly selective universities such as USP. A genuine expansion of university access would have important consequences regarding social mobility, given the high wage premium typically associated with attending selective universities, especially for underprivileged students (see, e.g., Hoekstra, 2009; Dale and Krueger, 2014).

We can exclude a pure general equilibrium effect explanation regarding admission offers because most applicants apply to both USP and UNICAMP simultaneously. The redistribution of offers by UNICAMP to the underprivileged is thus a genuine expansion of the underprivileged applicants' choice sets. Since USP is ranked slightly better and is slightly more selective than UNICAMP for most majors, expanding choice at UNICAMP is very unlikely to induce many applicants to enrol at UNICAMP rather than USP. It is possible, however, that some applicants obtained admission for different majors at USP and UNICAMP, with their preferred one at UNICAMP, thus freeing a slot at USP. 
Figure 6 shows the number of enrolled students coming from public high schools at UNICAMP and USP between 2001 and 2008. Considering only comparable majors that were offered at both USP and UNICAMP (top panel) does suggest some arbitrage may have taken place: the total number of public high school students enrolled at both universities remained constant, so the gains in UNICAMP enrollments were offset by losses at USP. However, once we consider all majors (bottom panel), the gains in enrollment by public school students at UNICAMP overcompensate the losses at USP, so that the overall effect is an increase in the total number of public high school students enrolled at both universities. Note, however, that we cannot exclude the possibility that a time trend plays a role here, given that the increase in the total number of enrollees at UNICAMP and USP was similar from 2001 to 2003. Interestingly, the total number of public high school students enrolled at both universities further increases in 2007, coinciding with the introduction of USP's own affirmative action policy. Taken together, these results indicate that even if we cannot exclude that some reshuffling occurred, the policies seem to expand access to selective universities for the underprivileged.

[ Figure 6 approximately here. ]

\section{Conclusion}

In this paper, we investigate the impact of UNICAMP's 2005 affirmative action policy on the pool of admitted students. Our results suggest a substantial increase in the representation of public high school students among UNICAMP's admitted students following the policy. The policy appears to have been successful in redistributing places at UNICAMP from those with more advantaged socio-economic backgrounds to those with less advantaged backgrounds.

Focusing on the results for performance in the years 2004 and 2005 for the second phase of the entrance exam does not yield evidence of a significant change in relative effort provision. This is true regardless of whether an applicant's entrance exam grade is expected to be below and above the cutoff, controlling for the difference between her grade and the cutoff. Overall, we find only small potential behavioural responses in reaction to UNICAMP's affirmative action policy, which do not seem large enough to affect who is admitted to the university.

One possible explanation for our findings might be that the highly competitive nature of the admission exam already induced applicants to be at a point where their effort cost function is fairly convex. That is, given the high stakes the effective elasticity of effort provision to the policy may be low before and after the policy. In that case, our results convey good news to policymakers, in that the behavioural responses predicted by economic 
theory are small enough not be policy relevant in environments characterised by strong competition. Our analysis suggests further that, in this context, a naive approximation is a good predictor of the actual policy effect. However, it is important to recognise that behavioural reactions could be more substantive in less competitive environments.

Overall, our findings suggest that affirmative action policies can be successful without inducing significant behavioural reactions or distortions, which appears encouraging from the policymaker's point of view. We show evidence that such a policy effectively expands access to selective universities and, therefore, can have an impact on social mobility. We believe that these results are also of interest to the policy debate in other countries, noting that the University of Bristol in the UK and Sciences Po in France, for example, now use admission rules awarding bonuses to applicants from underprivileged schools or neighbourhoods. Furthermore, a policy that conditions on the type of high school attended is likely to pass tests of constitutionality, more so than one that conditions on race. ${ }^{25}$

\section{References}

Antonovics, K. and Backes, B. (2014). 'The effect of banning affirmative action on human capital accumulation prior to college entry', IZA Journal of Labor Economics, vol. 3:5, ISSN 2193-8997.

Arcidiacono, P. and Lovenheim, M. (2016). 'Affirmative Action and the Quality-Fit TradeOff', Journal of Economic Literature, vol. 54(1), pp. 3-51.

Arcidiacono, P., Lovenheim, M. and Zhu, M. (2015). 'Affirmative Action in Undergraduate Education', Annual Review of Economics, vol. 7(1), pp. 487-518.

Arozamena, L. and Cantillon, E. (2004). 'Investment Incentives in Procurement Auctions', The Review of Economic Studies, vol. 71(1), pp. 1-18.

Assuncao, J. and Ferman, B. (2015). 'Does affirmative action enhance or undercut investment incentives? Evidence from quotas in Brazilian public universities', mimeo, pp. 1-47.

Ayres, I. and Cramton, P. (1996). 'Deficit Reduction Through Diversity: How Affirmative Action at the FCC Increased Auction Competition', Stanford Law Review, vol. 48(4), pp. 761-815, ISSN 00389765.

Backes, B. (2012). 'Do Affirmative Action Bans Lower Minority College Enrollment and Attainment? Evidence from Statewide Bans', Journal of Human Resources, vol. 47(2), pp. $435-455$.

\footnotetext{
${ }^{25}$ For example, the US Supreme Court took the view in Fisher vs. University of Texas 2013 that any consideration of racial criteria in affirmative action to ensure diversity must be narrowly tailored. The same argument was used to rule out the use of the bonus system implemented by the University of Michigan until 2003, whose design was similar to UNICAMP's, except that the bonus was based on race.
} 
Bertrand, M., Duflo, E. and Mullainathan, S. (2004). 'How much should we trust differencesin-differences estimates?', The Quarterly Journal of Economics, vol. 119(1), pp. 249-275.

Bertrand, M., Hanna, R. and Mullainathan, S. (2010). 'Affirmative action in education: Evidence from engineering college admissions in India', Journal of Public Economics, vol. 94(1-2), pp. 16-29.

Bodoh-Creed, A. and Hickman, B. (2016). 'College assignment as a large contest', Becker Friedman Institute for Research In Economics.

Bodoh-Creed, A. and Hickman, B. (2017). 'Pre-College Human Capital Investment and Affirmative Action: A Structural Policy Analysis of U.S. College Admissions', mimeo.

Calsamiglia, C., Franke, J. and Rey-Biel, P. (2013). 'The incentive effects of affirmative action in a real-effort tournament', Journal of Public Economics, vol. 98(0), pp. 15-31, ISSN 0047-2727.

Cameron, A.C., Gelbach, J.B. and Miller, D.L. (2011). 'Robust inference with multiway clustering', Journal of Business and Economic Statistics, vol. 29(2), pp. 238-249.

Cameron, A.C. and Miller, D.L. (2015). 'A practitioner's guide to cluster-robust inference', Journal of Human Resources, vol. 50(2), pp. 317-372.

Card, D. and Krueger, A.B. (2005). 'Would the Elimination of Affirmative Action Affect Highly Qualified Minority Applicants? Evidence from California and Texas', Industrial and Labor Relations Review, vol. 58(3), pp. 416-434.

Chin, A. and Prakash, N. (2011). 'The redistributive effects of political reservation for minorities: Evidence from India', Journal of Development Economics, vol. 96(2), pp. 265-277, ISSN 0304-3878.

Coate, S. and Loury, G.C. (1993a). 'Antidiscrimination enforcement and the problem of patronization', The American Economic Review, vol. 83(2), pp. 92-98.

Coate, S. and Loury, G.C. (1993b). 'Will affirmative-action policies eliminate negative stereotypes?', American Economic Review, vol. 83(5), pp. 1220-1240.

COMVEST (2005). 'Manual do vestibular UNCAMP', http://www.comvest.unicamp.br/vest2005/download/manual.pdf, (last accessed: 29 December 2017).

Cotton, C., Hickman, B.R. and Price, J.P. (2014). 'Affirmative Action and Human Capital Investment: Evidence from a Randomized Field Experiment', National Bureau of Economic Research.

Dale, S.B. and Krueger, A.B. (2014). 'Estimating the Effects of College Characteristics over the Career Using Administrative Earnings Data', Journal of Human Resources, vol. 49(2), pp. 323-358. 
Dickson, L.M. (2006). 'Does ending affirmative action in college admissions lower the percent of minority students applying to college?', Economics of Education Review, vol. 25(1), pp. 109-119.

Estevan, F., Gall, T. and Morin, L.P. (2016). 'Redistribution without distortion: Evidence from an affirmative action program at a large Brazilian university', University of Sao Paulo (FEA-USP).

Francis, A.M. and Tannuri-Pianto, M. (2012). 'Using Brazil's racial continuum to examine the short-term effects of affirmative action in higher education', Journal of Human Resources, vol. 47(3), pp. 754-784.

Franke, J. (2012). 'Affirmative action in contest games', European Journal of Political Economy, vol. 28(1), pp. 105-118.

Fryer, R. and Loury, G.C. (2005). 'Affirmative action and its mythology', Journal of Economic Perspectives, vol. 19(3), pp. 147-162.

Fryer, R.G. and Loury, G. (2013). 'Valuing diversity', Journal of Political Economy, vol. 121(4), pp. 747-774.

$\mathrm{Fu}$, Q. (2006). 'A theory of affirmative action in college admissions', Economic Inquiry, vol. 44(3), pp. 420-428, ISSN 1465-7295.

Gall, T., Legros, P. and Newman, A.F. (2015). 'College diversity and investment incentives', CEPR Discussion Paper No. DP10337.

Hinrichs, P. (2012). 'The Effects of Affirmative Action Bans on College Enrollment, Educational Attainment, and the Demographic Composition of Universities', Review of Economics and Statistics, vol. 94(3), pp. 712-722.

Hoekstra, M. (2009). 'The Effect of Attending the Flagship State University on Earnings: A Discontinuity-Based Approach', The Review of Economics and Statistics, vol. 91(4), pp. $717-724$.

Holzer, H. and Neumark, D. (2000). 'Assessing affirmative action', Journal of Economic Literature, vol. 38(3), pp. 483-568, ISSN 00220515.

Kleinke, M.U. (2006). 'O Vestibular Unicamp e a Inclusão Social: Experiências e Perspectivas', https://www.comvest.unicamp.br/paais/artigo7.pdf, (last accessed: 29 December 2017).

Krasnokutskaya, E. and Seim, K. (2011). 'Bid Preference Programs and Participation in Highway Procurement Auctions', American Economic Review, vol. 101(6), pp. 2653-2686.

Long, M.C. (2004). 'College applications and the effect of affirmative action', Journal of Econometrics, vol. 121(1-2), pp. 319-342. 
Long, M.C., Saenz, V. and Tienda, M. (2010). 'Policy Transparency and College Enrollment: Did the Texas Top Ten Percent Law Broaden Access to the Public Flagships?', The Annals of the American Academy of Political and Social Science, vol. 627(1), pp. 82-105.

Martin, I., Karabel, J. and Jaquez, S.W. (2005). 'High School Segregation and Access to the University of California', Educational Policy, vol. 19(2), pp. 308-330.

McCowan, T. (2007). 'Expansion without equity: An analysis of current policy on access to higher education in Brazil', Higher Education, vol. 53(5), pp. 579-598, ISSN 1573-174X.

Morin, L.P. (2015). 'Do Men and Women Respond Differently to Competition? Evidence from a Major Education Reform', Journal of Labor Economics, vol. 33(2), pp. 443-491.

Pande, R. (2003). 'Can Mandated Political Representation Increase Policy Influence for Disadvantaged Minorities? Theory and Evidence from India', American Economic Review, vol. 93(4), pp. 1132-1151.

Pedrosa, R., Dachs, J., Maia, R., Andrade, C. and Carvalho, B. (2007). 'Academic Performance, Students' Background and Affirmative Action at a Brazilian University', Higher Education Management and Policy, vol. 19(3), pp. 67-86.

Schotter, A. and Weigelt, K. (1992). 'Asymmetric Tournaments, Equal Opportunity Laws, and Affirmative Action: Some Experimental Results', The Quarterly Journal of Economics, vol. 107(2), pp. 511-539.

Tessler, L. (2006). 'Ação afirmativa sem cotas: O Programa de Ação Afirmativa e Inclusão Social da Unicamp', https://www.comvest.unicamp.br/paais/artigo1.pdf, (last accessed: 29 December 2017).

The Sutton Trust (2011). 'Degree of success - university chances by individual school', http://www.suttontrust.com/wp-content/uploads/2011/07/sutton-trust-hedestination-report-final.pdf, (last accessed: 29 December 2017). 


\section{Appendix A - UNICAMP Admission Rules}

The final ranking of the applicants depends on the final grade (nota padronizada de opção (NPO)), which is calculated using the following standardised grades: (i) final grade of Phase 1 (that may include ENEM) with a weight of 2; (ii) grades of Phase 2 priority discipline exams, each receiving a weight 2; (iii) grade of the aptitude test for Architecture and Urban Studies and Arts (but not Dentistry) with a weight of 2, if applicable; (iv) grade of other Phase 2 non priority disciplines exams (and aptitude test for Dentistry) with a weight of 1. NPO is calculated for each of the major choices (up to three) made by the applicant.

The grades (i)-(iv) are standardised using the formula:

$$
N P=\frac{(N-M) \times 100}{D}+500
$$

where $N P$ is the applicant's standardised grade, $N$ is the grade the applicant received in the exam, $M$ and $D$ are the average grade and the standard deviation of the grades in the exam. Until 2003, the standardisation of Phase 2 exams was done separately for applicants of majors within the four areas. Starting in 2004, the standardisation considers the grades of Phase 2 exams of all students who participated in the exam. For the final grade of Phase 1, only the grades of candidates who passed Phase 1 are considered. Once grades (i)-(iv) are standardised, the NPO of a candidate is calculated as the weighted average of the standardised grades, with the weights given above.

Until 2003, only the applicants who obtained the priority discipline cutoff grade (nota de corte prioritária, (NCP)) were admitted. Eligible candidates were then ranked in decreasing order of NPO and were admitted until all slots were attributed for candidates choosing the major as first choice. Once all the eligible candidates who ranked the major as their first option were admitted, candidates who chose the major as their second option (and then their third option) were admitted if they had not been admitted to their first option (or second option, respectively). If there were still some slots remaining, then the candidates who applied for (and have not been admitted for) other majors within the same group would be admitted. After this has been done or if there is only one major in the group, then they would admit applicants with NPO larger than the last candidate admitted under the criterion just explained, even if they do not satisfy the NCP criterion. Finally, if there are still slots available, candidates for other majors who were not admitted can be called. This is be done by forming new groups and recalculating the standardised grade within these new groups.

Since 2004, two grades are associated with the priority subjects, which are relevant for admission: the priority discipline cutoff grade (nota de corte prioritária, (NCP)) and the major minimum grade (nota mínima de opção (NMO)). From 2004 to 2006, these cutoffs were defined based on the non-standardised grades. In 2007 and 2008, the thresholds were based on the standardised grades.

The candidates are ranked in decreasing order of NPO and accepted based on the following rules:

1. Those who opted for the major as their first option and obtained, in the priority subjects, (non-standardised or standardised) grades that are larger or equal to the 
major's NMO are accepted.

2. If there are still slots available, applicants who opted for the major as their second or third choice, with (non-standardised or standardised) grades in the priority subjects larger or equal to NMO, up to a maximum of $20 \%$ of the total slots available for the major.

3. If there are still slots available, applicants who opted for the major as their first option and who obtained (non-standardised or standardised) grades that are larger or equal to the major's NCP.

4. If there are still slots available, applicants who opted for the course as second or third options and who obtained (non-standardised or standardised) grades that are larger or equal to the major's NMO.

5. If there are still slots available, applicants who opted for the course as second or third options and who obtained (non-standardised or standardised) grades that are larger or equal to the major's NCP.

6. If there are still slots available, candidates who opted for the major, independently of the choice rank.

7. If there are still slots available, applicants who opted for similar majors, as determined by the Office of the Vice-President, Research.

In case of a draw, the applicant admitted will be the one with the larger standardised grade in a priority subject in the order they are presented in the priority discipline list, or in the order the exams take place in Phase 2. 


\section{Appendix B - Figures and Tables}

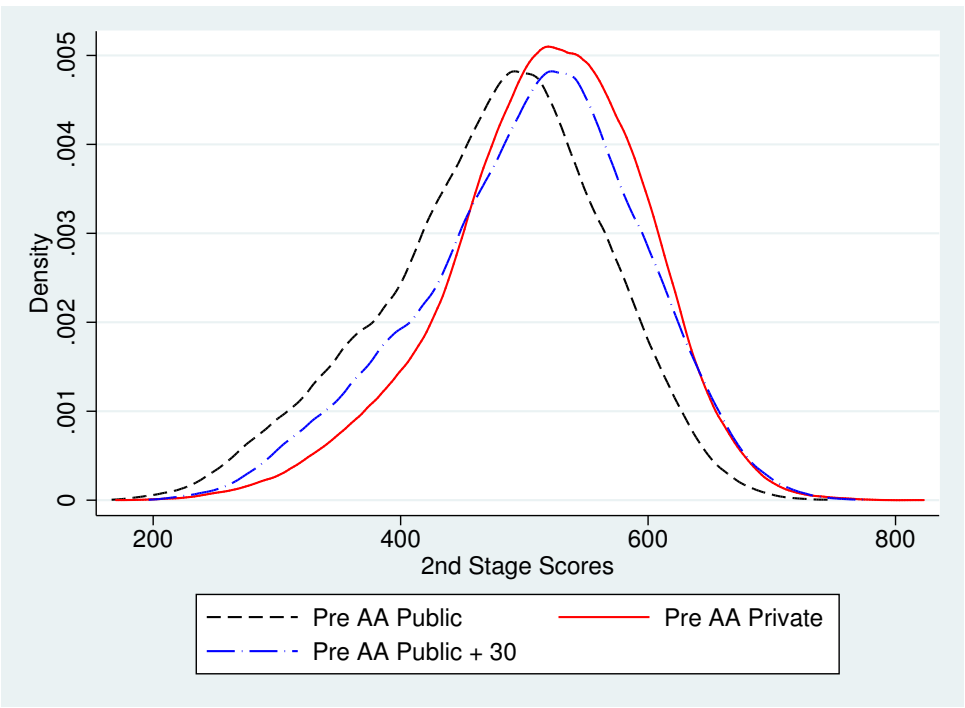

Figure 1: Distributions of Admission Exam Final Scores (NPOs) Prior to 2005

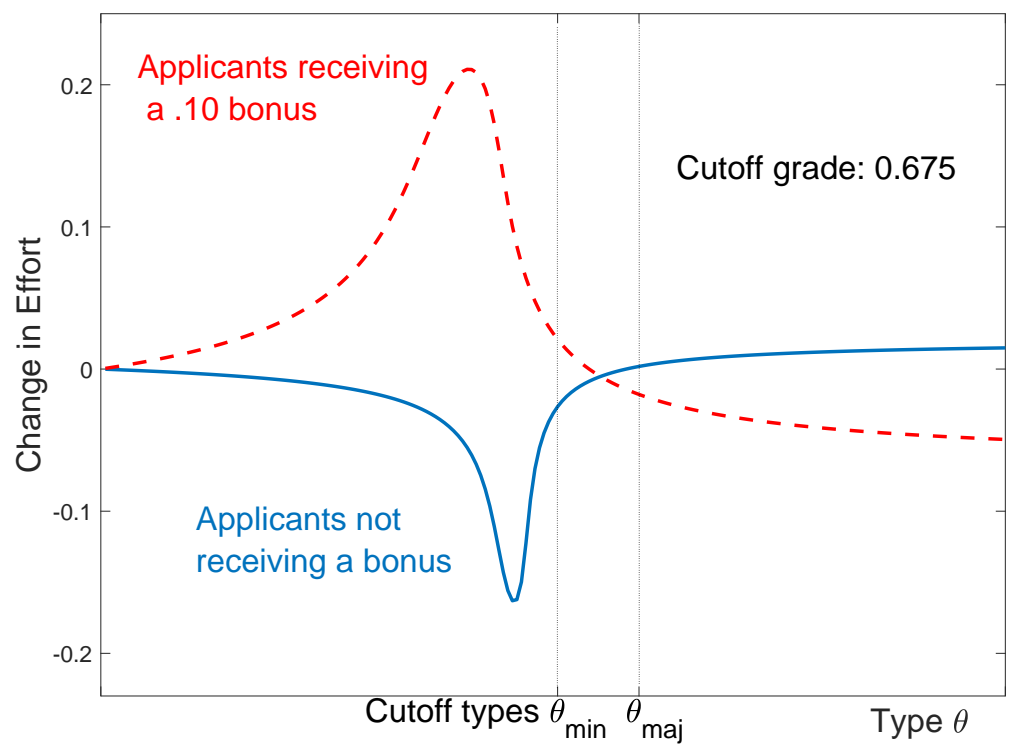

Figure 2: Difference in Effort Choice: Change in equilibrium effort induced by the policy for minority and majority applicants by cost type. 

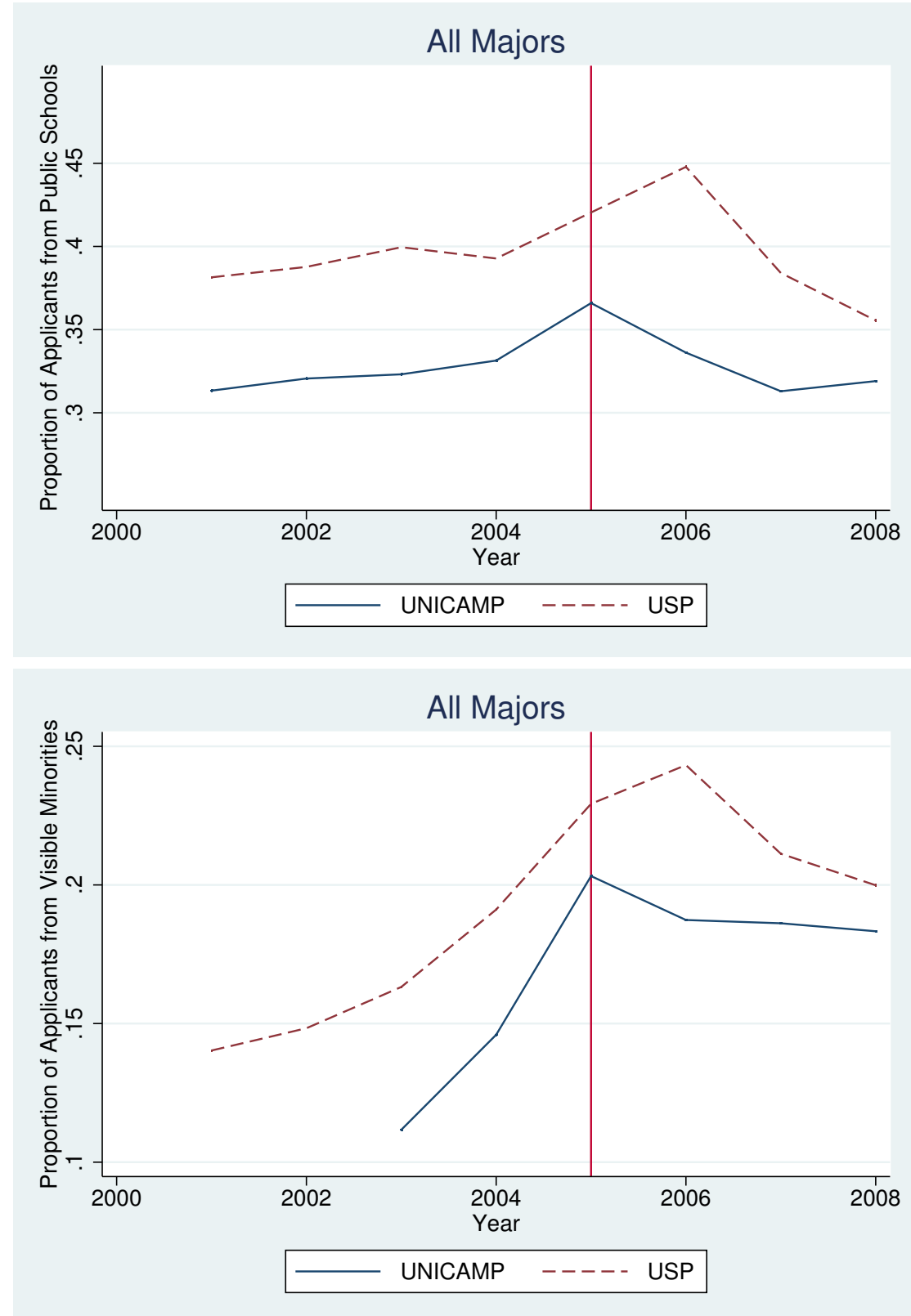

Figure 3: UNICAMP and USP Applicants

Note: The proportions of public school and visible minority applicants at UNICAMP is different from Tables 1 and 2 since we do not exclude the applicants who did not show up to $P_{1}$, as this information is not available for USP. The graph is similar if we restrict the sample to majors that are offered by both institutions. Data from USP excludes EACH majors, as explained in Section 3. 

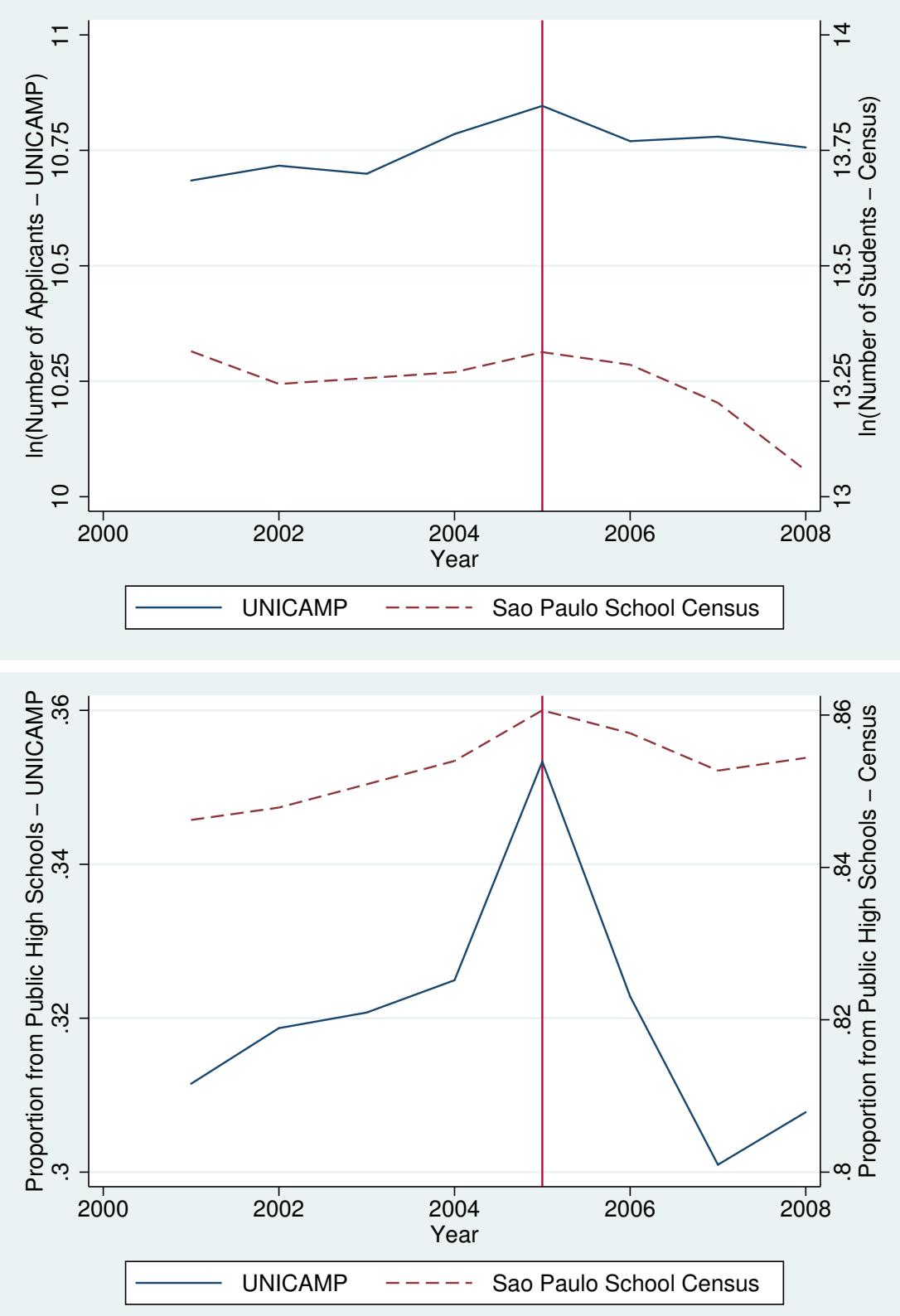

Figure 4: High School Seniors and UNICAMP Applicants 

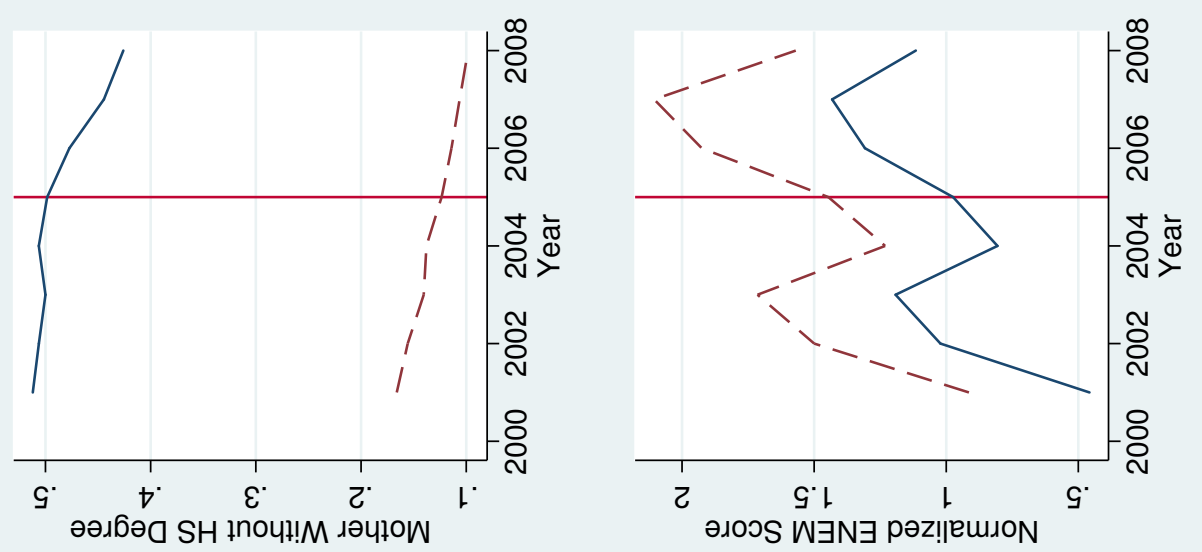

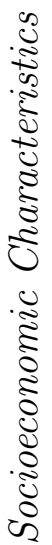
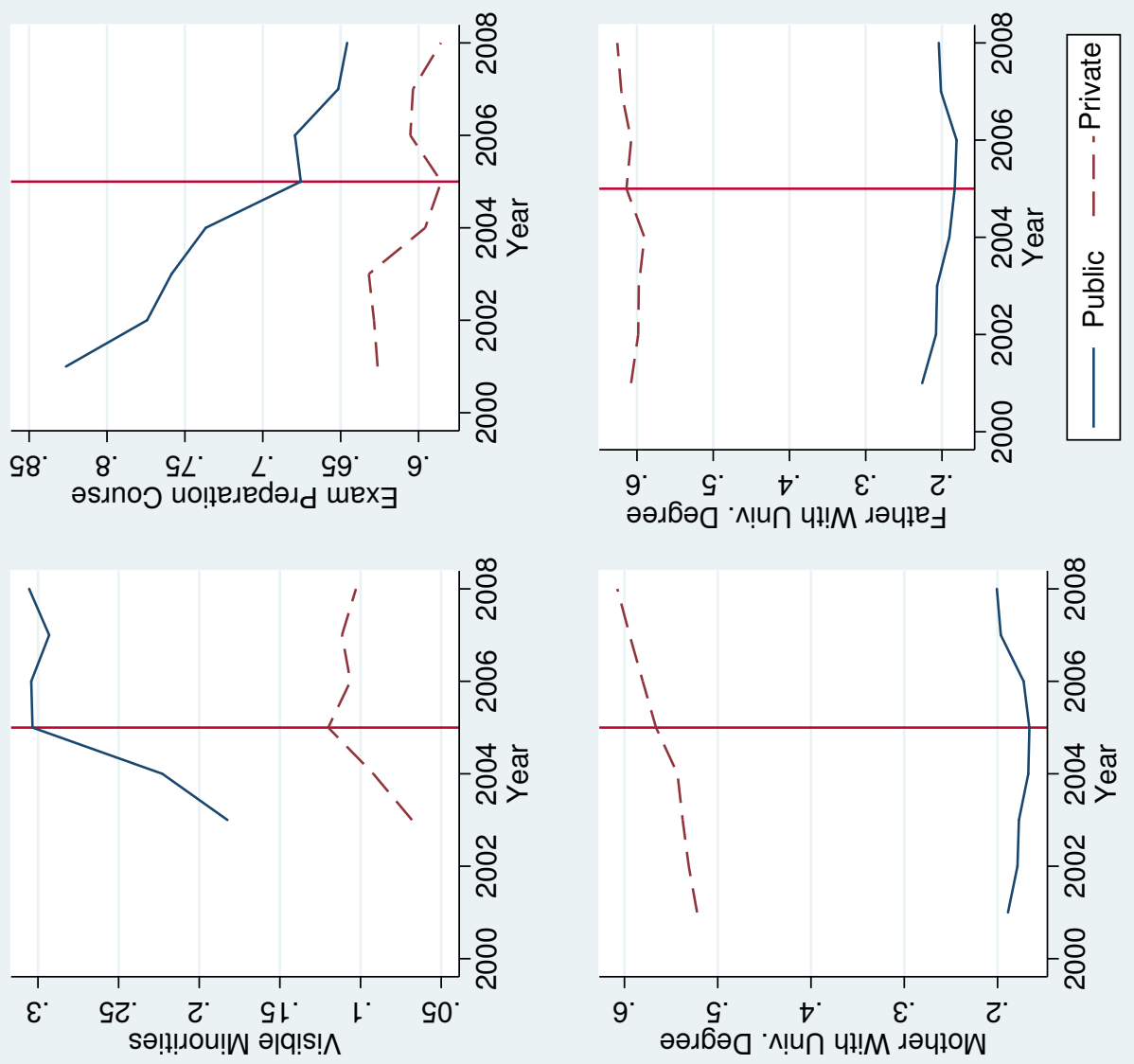

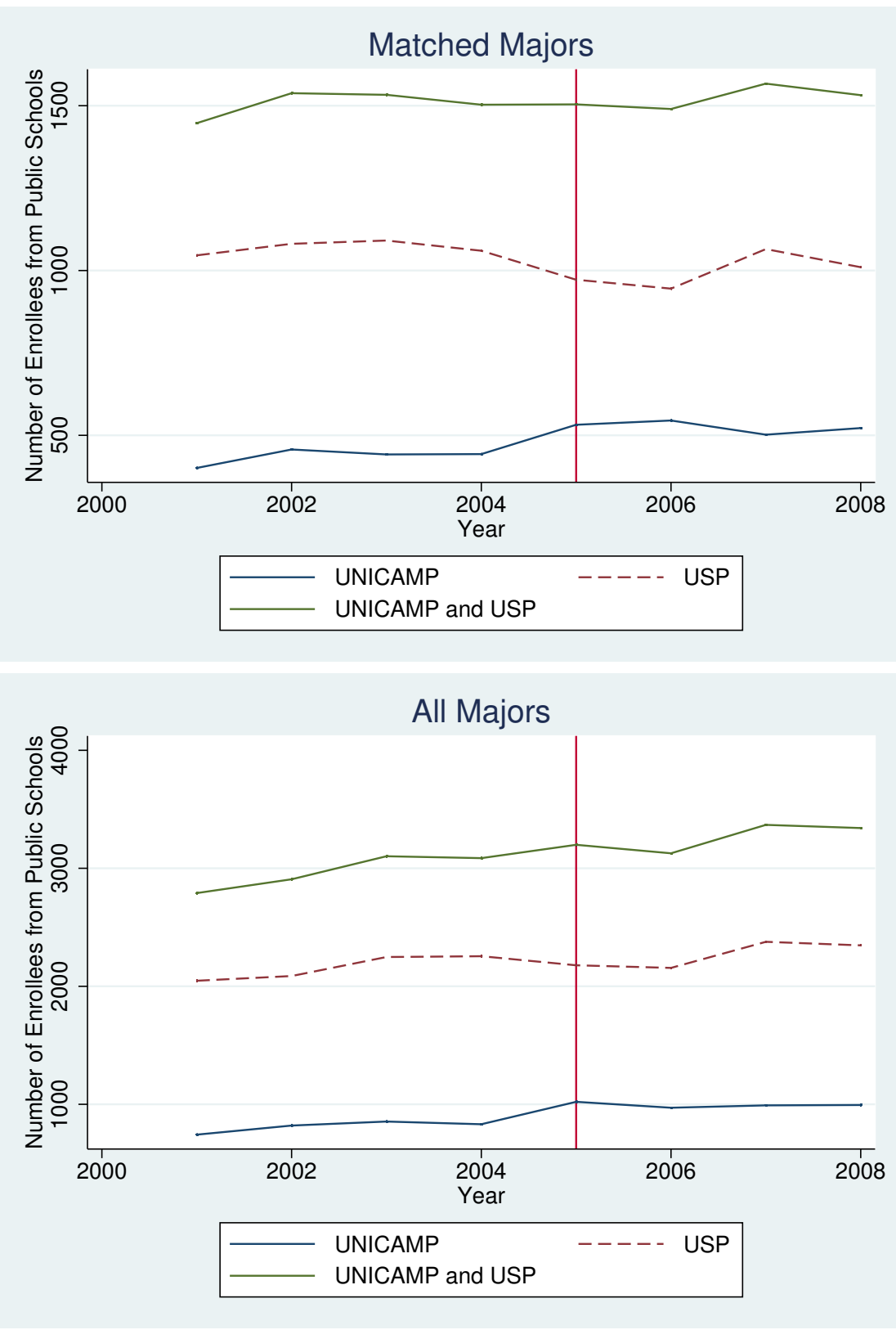

Figure 6: UNICAMP and USP Enrollees

Note: Data from USP excludes EACH majors, as explained in Section 3. 


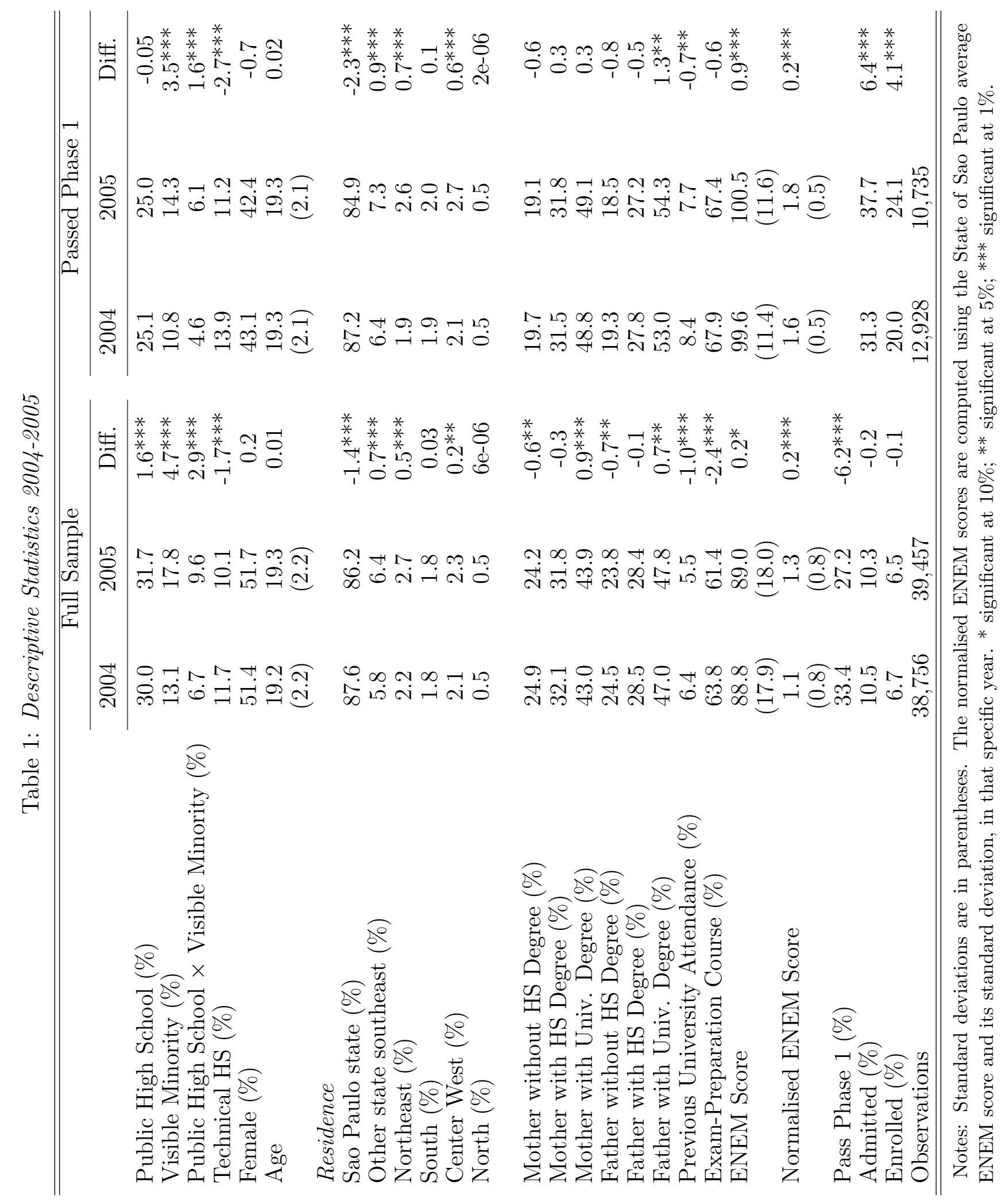




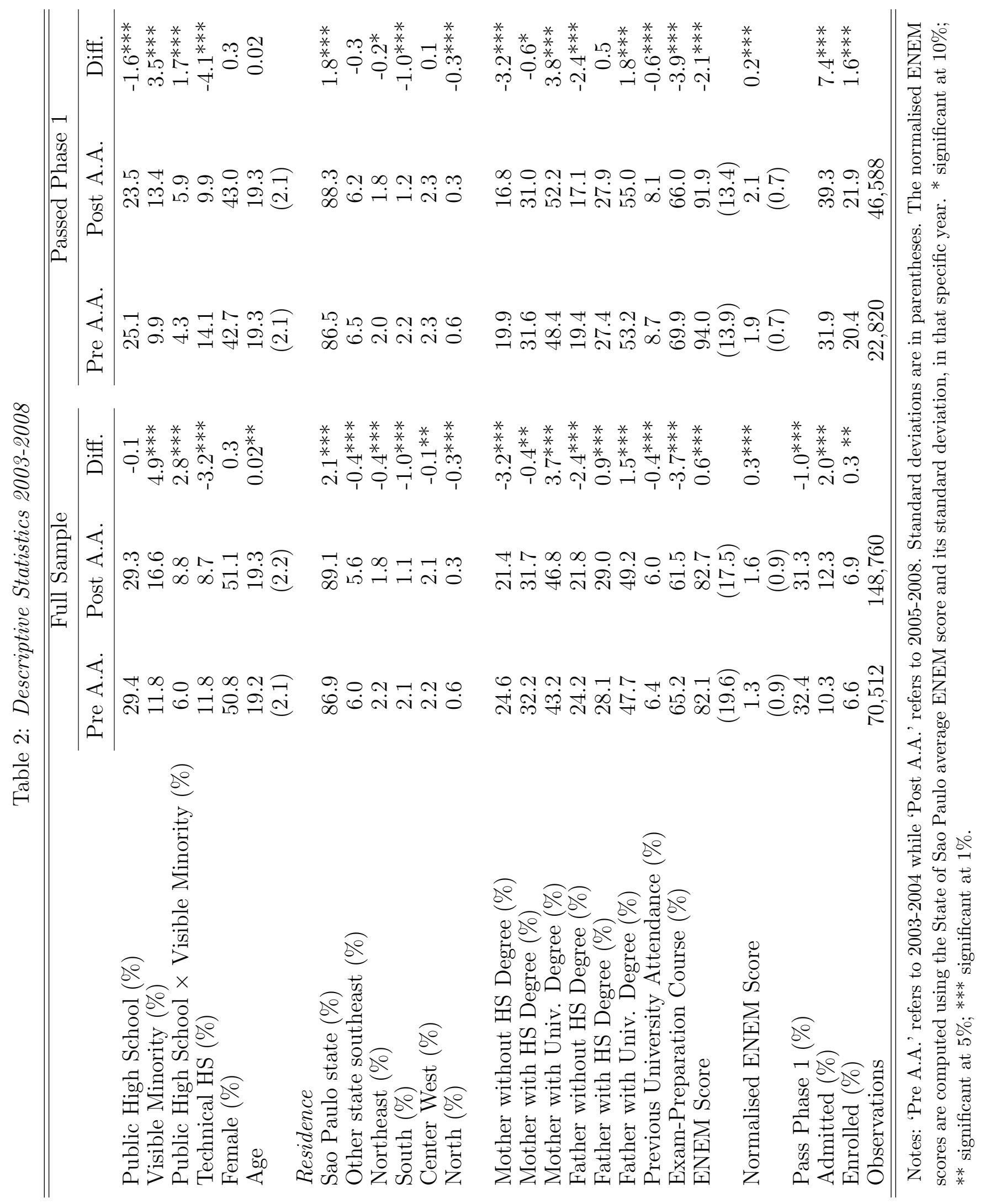


Table 3: Admission and Affirmative Action, 2004-2005

\begin{tabular}{|c|c|c|c|c|c|}
\hline \multirow{3}{*}{ Public High School } & (1) & $(2)$ & $(3)$ & $\overline{(4)}$ & $(5)$ \\
\hline & $-0.024^{*}$ & $-0.023^{*}$ & $0.017^{*}$ & $-0.011^{*}$ & $-0.014^{* *}$ \\
\hline & $(0.013)$ & $(0.013)$ & $(0.010)$ & $(0.006)$ & $(0.006)$ \\
\hline \multirow[t]{2}{*}{ Visible Minority } & $-0.013^{* * *}$ & $-0.011^{* *}$ & $-6.1 \mathrm{e}-05$ & 0.001 & 0.002 \\
\hline & $(0.004)$ & $(0.005)$ & $(0.004)$ & $(0.005)$ & $(0.006)$ \\
\hline \multirow[t]{2}{*}{ Visible Minority $\times$ Public HS } & $-0.013^{* *}$ & $-0.017^{* *}$ & 0.001 & -0.001 & $4.4 \mathrm{e}-04$ \\
\hline & $(0.006)$ & $(0.008)$ & $(0.008)$ & $(0.009)$ & $(0.009)$ \\
\hline \multirow[t]{2}{*}{ Public HS × AA Years } & $0.023^{* * *}$ & $0.021^{* * *}$ & $0.025^{* * *}$ & $0.027 * * *$ & $0.028 * * *$ \\
\hline & $(0.006)$ & $(0.007)$ & $(0.007)$ & $(0.007)$ & $(0.006)$ \\
\hline \multirow[t]{2}{*}{ Visible Minority $\times$ AA Years } & -0.004 & -0.007 & $-0.012^{* *}$ & $-0.013^{* *}$ & $-0.016^{* * *}$ \\
\hline & $(0.005)$ & $(0.006)$ & $(0.006)$ & $(0.006)$ & $(0.006)$ \\
\hline \multirow[t]{2}{*}{ Visible Minority $\times$ Public $\mathrm{HS} \times \mathrm{AA}$ Years } & & 0.008 & 0.010 & 0.015 & 0.015 \\
\hline & & $(0.008)$ & $(0.008)$ & $(0.010)$ & $(0.010)$ \\
\hline \multirow[t]{2}{*}{ Normalised ENEM Score } & & & $0.101^{* * *}$ & $0.122^{* * *}$ & $0.124^{* * *}$ \\
\hline & & & $(0.015)$ & $(0.015)$ & $(0.015)$ \\
\hline Year Fixed Effects & Yes & Yes & Yes & Yes & Yes \\
\hline Age and Gender Controls & No & No & Yes & Yes & Yes \\
\hline Parental Education Controls & No & No & Yes & Yes & Yes \\
\hline University Experience Control & No & No & Yes & Yes & Yes \\
\hline Major Fixed Effects & No & No & No & Yes & Yes \\
\hline Municipality Fixed Effects & No & No & No & No & Yes \\
\hline Number of Observations & 78,213 & 78,213 & 78,213 & 78,213 & 78,213 \\
\hline Number of Major Clusters & 59 & 59 & 59 & 59 & 59 \\
\hline Number of Municipality Clusters & 1,540 & 1,540 & 1,540 & 1,540 & 1,540 \\
\hline
\end{tabular}

Notes: The dependent variable is a binary variable equal to one if the applicant was accepted to UNICAMP, zero otherwise. The ENEM score is normalised each year using the Sao Paulo state-level average and standard deviation. Public High School is a binary variable equal to one if the applicant was enrolled in a Brazilian public school for the duration of her/his secondary education, and zero otherwise. Visible Minority is a binary variable equal to one if the applicant is black, mulatto or native, and zero otherwise. AA Years is a binary variable equal to one if the year is 2005, zero otherwise. The university experience control consists of a dummy variable equal to one if the applicant has previous university experience, and zero otherwise. We control for age using a quartic function in age. 'Trainees' are excluded. Two-way cluster-robust standard errors (at the major and municipality levels) are shown in parentheses. * significant at $10 \%$; ${ }^{* *}$ significant at $5 \%$; ${ }^{* *}$ significant at $1 \%$. 
Table 4: Admission and Affirmative Action, 2003-2008

\begin{tabular}{|c|c|c|c|c|c|}
\hline & (1) & $(2)$ & $(3)$ & $(4)$ & $(5)$ \\
\hline \multirow{2}{*}{ Public High School } & -0.019 & -0.019 & $0.027^{* * *}$ & -0.008 & $-0.011^{* *}$ \\
\hline & $(0.012)$ & $(0.012)$ & $(0.009)$ & $(0.005)$ & $(0.005)$ \\
\hline \multirow[t]{2}{*}{ Visible Minority } & $-0.009^{*}$ & -0.006 & 0.003 & 0.004 & 0.004 \\
\hline & $(0.005)$ & $(0.007)$ & $(0.005)$ & $(0.005)$ & $(0.005)$ \\
\hline \multirow[t]{2}{*}{ Visible Minority $\times$ Public HS } & $-0.014^{* * *}$ & $-0.019 * * *$ & $9 \mathrm{e}-05$ & -0.004 & -0.003 \\
\hline & $(0.004)$ & $(0.007)$ & $(0.007)$ & $(0.008)$ & $(0.008)$ \\
\hline \multirow[t]{2}{*}{ Public HS × AA Years } & $0.020 * * *$ & $0.018^{* * *}$ & $0.025^{* * *}$ & $0.031^{* * *}$ & $0.031^{* * *}$ \\
\hline & $(0.005)$ & $(0.006)$ & $(0.005)$ & $(0.006)$ & $(0.006)$ \\
\hline \multirow[t]{2}{*}{ Visible Minority $\times$ AA Years } & $-0.011^{* *}$ & $-0.014^{* *}$ & $-0.016^{* *}$ & $-0.015^{* *}$ & $-0.017^{* *}$ \\
\hline & $(0.004)$ & $(0.007)$ & $(0.007)$ & $(0.007)$ & $(0.008)$ \\
\hline \multirow[t]{2}{*}{ Visible Minority $\times$ Public $\mathrm{HS} \times \mathrm{AA}$ Years } & & 0.007 & 0.008 & 0.011 & 0.013 \\
\hline & & $(0.009)$ & $(0.008)$ & $(0.009)$ & $(0.010)$ \\
\hline \multirow[t]{2}{*}{ Normalised ENEM Score } & & & $0.105^{* * *}$ & $0.131^{* * *}$ & $0.132^{* * *}$ \\
\hline & & & $(0.017)$ & $(0.017)$ & $(0.017)$ \\
\hline Year Fixed Effects & Yes & Yes & Yes & Yes & Yes \\
\hline Age and Gender Controls & No & No & Yes & Yes & Yes \\
\hline Parental Education Controls & No & No & Yes & Yes & Yes \\
\hline University Experience Control & No & No & Yes & Yes & Yes \\
\hline Major Fixed Effects & No & No & No & Yes & Yes \\
\hline Municipality Fixed Effects & No & No & No & No & Yes \\
\hline Number of Observations & 219,272 & 219,272 & 219,272 & 219,272 & 219,272 \\
\hline Number of Major Clusters & 61 & 61 & 61 & 61 & 61 \\
\hline Number of Municipality Clusters & 2,076 & 2,076 & 2,076 & 2,076 & 2,076 \\
\hline
\end{tabular}

Notes: The dependent variable is a binary variable equal to one if the applicant was accepted to UNICAMP, zero otherwise. The ENEM score is normalised each year using the Sao Paulo state-level average and standard deviation. Public High School is a binary variable equal to one if the applicant was enrolled in a Brazilian public school for the duration of her/his secondary education, and zero otherwise. Visible Minority is a binary variable equal to one if the applicant is black, mulatto or native, and zero otherwise. AA Years is a binary variable equal to one if the year is 2005 or above, zero otherwise. The university experience control consists of a dummy variable equal to one if the applicant has previous university experience, and zero otherwise. We control for age using a quartic function in age. 'Trainees' are excluded. Two-way cluster-robust standard errors (at the major and municipality levels) are shown in parentheses. ${ }^{*}$ significant at $10 \% ;{ }^{* *}$ significant at $5 \%$; ${ }^{* *}$ significant at $1 \%$. 
Table 5: Descriptive Statistics of 'Displacing' and 'Displaced' (2005)

\begin{tabular}{|c|c|c|c|c|}
\hline & Displacing & Displaced & Difference & Obs. \\
\hline \multicolumn{5}{|l|}{ A. Applicant Characteristics } \\
\hline Public High School (\%) & 98.85 & 3.49 & $95.36 * * *$ & 536 \\
\hline Visible Minority (\%) & 33.08 & 10.81 & $22.27 * * *$ & 519 \\
\hline Technical (\%) & 25.75 & 8.21 & $17.54^{* * *}$ & 536 \\
\hline Female $(\%)$ & 47.39 & 47.39 & 0.00 & 536 \\
\hline Age & $\begin{array}{l}20.43 \\
(3.66)\end{array}$ & $\begin{array}{l}19.40 \\
(2.43)\end{array}$ & $1.03^{* * *}$ & 536 \\
\hline ENEM Score & $\begin{array}{c}100.9 \\
(11.00)\end{array}$ & $\begin{array}{c}101.6 \\
(10.62)\end{array}$ & -0.6 & 504 \\
\hline Normalised ENEM Score & $\begin{array}{c}1.82 \\
(0.48)\end{array}$ & $\begin{array}{c}1.85 \\
(0.47)\end{array}$ & -0.03 & 504 \\
\hline Missing ENEM Score (\%) & 5.97 & 5.97 & 0.00 & 536 \\
\hline Financed by Family (\%) & 85.71 & 94.16 & $-8.45^{* *}$ & 516 \\
\hline Financially Help Family (\%) & 9.27 & 3.11 & $6.15^{* * *}$ & 516 \\
\hline Work $32+$ Hours/Week (\%) & 13.13 & 5.84 & $7.29 * * *$ & 516 \\
\hline \multicolumn{5}{|l|}{ B. Applicant Family Characteristics } \\
\hline Mother with Manual Occ. (\%) & 12.79 & 3.15 & $9.64^{* * *}$ & 512 \\
\hline Mother with 'Mid-Top Occ.' (\%) & 8.91 & 29.92 & $-21.01 * * *$ & 512 \\
\hline Mother with 'Top Occ.' (\%) & 1.16 & 2.36 & -1.20 & 512 \\
\hline Father with Manual Occ. (\%) & 20.70 & 3.16 & $17.54^{* * *}$ & 509 \\
\hline Father with 'Mid-Top Occ.' (\%) & 21.88 & 51.78 & $-29.90 * * *$ & 509 \\
\hline Father with 'Top Occ.' (\%) & 0.78 & 3.16 & $-2.38^{*}$ & 509 \\
\hline Mother without HS Degree (\%) & 39.22 & 13.73 & $25.49 * * *$ & 510 \\
\hline Mother with Univ. Degree (\%) & 25.49 & 52.94 & $-27.45^{* * *}$ & 510 \\
\hline Father without HS Degree (\%) & 37.80 & 16.54 & $21.26 * * *$ & 508 \\
\hline Father with Univ. Degree (\%) & 31.10 & 59.06 & $-27.95^{* * *}$ & 508 \\
\hline Family Income & $\begin{array}{c}2,212 \\
(1,896)\end{array}$ & $\begin{array}{c}4,152 \\
(3,185)\end{array}$ & $-1,940 * * *$ & 503 \\
\hline Home Computer (\%) & 78.85 & 92.19 & $-13.34^{* * *}$ & 516 \\
\hline Applicants & 268 & 268 & & \\
\hline
\end{tabular}

Notes: 'Top Occ.' is defined as an occupation in "high politics, business, or owner of a large company" while 'Mid-Top Occ.' is defined as "self-employed, manager, owner of a medium company." 'Manual O'cc. includes both specialised and non-specialised occupations. Standard deviations are in parentheses. ${ }^{*}$ significant at $10 \% ;{ }^{* *}$ significant at $5 \% ; * * *$ significant at $1 \%$. 
Table 6: Phase 1 Success and Affirmative Action, 2004-2005

\begin{tabular}{|c|c|c|c|c|c|}
\hline & $(1)$ & $\overline{(2)}$ & $(3)$ & $\overline{(4)}$ & $(5)$ \\
\hline \multirow[t]{2}{*}{ Public High School } & $-0.067^{*}$ & $-0.067^{*}$ & 0.017 & $-0.046^{* * *}$ & $-0.046^{* * *}$ \\
\hline & $(0.035)$ & $(0.034)$ & $(0.026)$ & $(0.013)$ & $(0.013)$ \\
\hline \multirow[t]{2}{*}{ Visible Minority } & $-0.036^{* * *}$ & $-0.035 * * *$ & $-0.015^{* *}$ & -0.012 & $-0.020 * *$ \\
\hline & $(0.008)$ & $(0.008)$ & $(0.006)$ & $(0.009)$ & $(0.009)$ \\
\hline \multirow[t]{2}{*}{ Visible Minority $\times$ Public HS } & $-0.029 * * *$ & $-0.031^{* *}$ & 0.011 & 0.004 & 0.013 \\
\hline & $(0.010)$ & $(0.014)$ & $(0.010)$ & $(0.010)$ & $(0.010)$ \\
\hline \multirow[t]{2}{*}{ Public HS × AA Years } & -0.001 & -0.002 & 0.007 & 0.011 & 0.013 \\
\hline & $(0.011)$ & $(0.011)$ & $(0.010)$ & $(0.011)$ & $(0.011)$ \\
\hline \multirow[t]{2}{*}{ Visible Minority $\times$ AA Years } & 0.005 & 0.004 & -0.007 & -0.006 & -0.004 \\
\hline & $(0.007)$ & $(0.009)$ & $(0.010)$ & $(0.009)$ & $(0.008)$ \\
\hline \multirow{2}{*}{ Visible Minority $\times$ Public HS $\times$ AA Years } & & 0.003 & 0.007 & 0.017 & 0.010 \\
\hline & & $(0.014)$ & $(0.013)$ & $(0.012)$ & $(0.012)$ \\
\hline \multirow[t]{2}{*}{ Normalised ENEM Score } & & & $0.233^{* * *}$ & $0.276^{* * *}$ & $0.276^{* * *}$ \\
\hline & & & $(0.031)$ & $(0.026)$ & $(0.025)$ \\
\hline Year Fixed Effects & Yes & Yes & Yes & Yes & Yes \\
\hline Age and Gender Controls & No & No & Yes & Yes & Yes \\
\hline Parental Education Controls & No & No & Yes & Yes & Yes \\
\hline University Experience Control & No & No & Yes & Yes & Yes \\
\hline Major Fixed Effects & No & No & No & Yes & Yes \\
\hline Municipality Fixed Effects & No & No & No & No & Yes \\
\hline Number of Observations & 78,213 & 78,213 & 78,213 & 78,213 & 78,213 \\
\hline Number of Major Clusters & 59 & 59 & 59 & 59 & 59 \\
\hline Number of Municipality Clusters & 1,540 & 1,540 & 1,540 & 1,540 & 1,540 \\
\hline
\end{tabular}

Notes: The dependent variable is a binary variable equal to one if the applicant passed Phase 1 of UNICAMP's admission exam, zero otherwise. The ENEM score is normalised each year using the Sao Paulo state-level average and standard deviation. Public High School is a binary variable equal to one if the applicant was enrolled in a Brazilian public school for the duration of her/his secondary education, and zero otherwise. Visible Minority is a binary variable equal to one if the applicant is black, mulatto or native, and zero otherwise. AA Years is a binary variable equal to one if the year is 2005, zero otherwise. The university experience control consists of a dummy variable equal to one if the applicant has previous university experience, and zero otherwise. We control for age using a quartic function in age. 'Trainees' are excluded. Two-way cluster-robust standard errors (at the major and municipality levels) are shown in parentheses. ${ }^{*}$ significant at $10 \% ;{ }^{* *}$ significant at $5 \%$; ${ }^{* *}$ significant at $1 \%$. 
Table 7: Performance in Phase 2, 2004-2005

\begin{tabular}{lccccc}
\hline \hline & $(1)$ & $(2)$ & $(3)$ & $(4)$ & $(5)$ \\
Public High School & $-0.417^{* * *}$ & $-0.419^{* * *}$ & $-0.295^{* * *}$ & $-0.115^{* * *}$ & $-0.120^{* * *}$ \\
& $(0.046)$ & $(0.046)$ & $(0.043)$ & $(0.016)$ & $(0.016)$ \\
Visible Minority & $-0.078^{* * *}$ & $-0.085^{* *}$ & -0.044 & -0.021 & -0.026 \\
& $(0.026)$ & $(0.035)$ & $(0.035)$ & $(0.024)$ & $(0.024)$ \\
Visible Minority $\times$ Public HS & -0.009 & 0.007 & 0.029 & -0.016 & 0.002 \\
& $(0.031)$ & $(0.050)$ & $(0.049)$ & $(0.038)$ & $(0.036)$ \\
Public HS $\times$ AA Years & 0.009 & 0.014 & 0.015 & 0.007 & 0.014 \\
& $(0.026)$ & $(0.029)$ & $(0.029)$ & $(0.023)$ & $(0.022)$ \\
Visible Minority $\times$ AA Years & -0.009 & 0.004 & 0.005 & -0.006 & -0.023 \\
& $(0.021)$ & $(0.028)$ & $(0.029)$ & $(0.024)$ & $(0.026)$ \\
Visible Minority $\times$ Public HS $\times$ AA Years & & -0.032 & -0.034 & 0.013 & 0.010 \\
& & $(0.057)$ & $(0.052)$ & $(0.043)$ & $(0.043)$ \\
Normalised ENEM Score & $1.155^{* * *}$ & $1.155^{* * *}$ & $1.151^{* * *}$ & $0.732^{* * *}$ & $0.737^{* * *}$ \\
& $(0.097)$ & $(0.097)$ & $(0.093)$ & $(0.036)$ & $(0.034)$ \\
Year Fixed Effects & Yes & Yes & Yes & Yes & Yes \\
Age and Gender Controls & No & No & Yes & Yes & Yes \\
Parental Education Controls & No & No & Yes & Yes & Yes \\
University Experience Control & No & No & Yes & Yes & Yes \\
Major Fixed Effects & No & No & No & Yes & Yes \\
Municipality Fixed Effects & No & No & No & No & Yes \\
\hline Number of Observations & 21,990 & 21,990 & 21,990 & 21,990 & 21,990 \\
Number of Major Clusters & 59 & 59 & 59 & 59 & 59 \\
Number of Municipality Clusters & 828 & 828 & 828 & 828 & 828 \\
\hline \hline
\end{tabular}

Notes: The dependent variable is the normalised Phase 2 test score, excluding Phase 1 performance. This score is normalised such that, every year, the mean and the variance of these scores are 0 and 1, respectively. The ENEM score is normalised each year using the Sao Paulo state-level average and standard deviation. Public High School is a binary variable equal to one if the applicant was enrolled in a Brazilian public school for the duration of her/his secondary education, and zero otherwise. Visible Minority is a binary variable equal to one if the applicant is black, mulatto or native, and zero otherwise. AA Years is a binary variable equal to one if the year is 2005, zero otherwise. The university experience control consists of a dummy variable equal to one if the applicant has previous university experience, and zero otherwise. We control for age using a quartic function in age. 'Trainees' are excluded. Two-way cluster-robust standard errors (at the major and municipality levels) are shown in parentheses. ${ }^{*}$ significant at $10 \% ;{ }^{* *}$ significant at $5 \%$; ** significant at $1 \%$. 
Table 8: Performance in Phase 2, 2004-2005 (Trainees Only)

\begin{tabular}{lcccc}
\hline \hline & $(1)$ & $(2)$ & $(3)$ & $(4)$ \\
Public High School & $-0.337^{* * *}$ & $-0.400^{* * *}$ & $-0.235^{*}$ & $-0.334^{* * *}$ \\
Visible Minority & $(0.094)$ & $(0.145)$ & $(0.127)$ & $(0.126)$ \\
& -0.131 & -0.148 & -0.143 & $-0.288^{* * *}$ \\
AA Years & $(0.127)$ & $(0.128)$ & $(0.101)$ & $(0.108)$ \\
& -0.063 & -0.040 & -0.035 & -0.041 \\
Normalised ENEM Score & $(0.094)$ & $(0.102)$ & $(0.063)$ & $(0.064)$ \\
& $1.034^{* * *}$ & $1.032^{* * *}$ & $0.814^{* * *}$ & $0.794^{* * *}$ \\
Age Controls & $(0.067)$ & $(0.079)$ & $(0.065)$ & $(0.041)$ \\
Parental Education Controls & No & Yes & Yes & Yes \\
University Experience Control & No & Yes & Yes & Yes \\
Major Fixed Effects & No & Yes & Yes & Yes \\
Municipality Fixed Effects & No & No & Yes & Yes \\
\hline Number of Observations & 571 & 571 & 571 & Yes \\
Number of Major Clusters & 53 & 53 & 53 & 531 \\
Number of Municipality Clusters & 115 & 115 & 115 & 115 \\
\hline \hline
\end{tabular}

Notes: The dependent variable is the normalised Phase 2 test score, excluding Phase 1 performance. This score is normalised such that, every year, the mean and the variance of the scores of applicants writing the test for admission (not as a practice test) are 0 and 1 , respectively. The ENEM score is normalised each year using the Sao Paulo state-level average and standard deviation. Public High School is a binary variable equal to one if the applicant was enrolled in a Brazilian public school for the duration of her/his secondary education, and zero otherwise. Visible Minority is a binary variable equal to one if the applicant is black, mulatto or native, and zero otherwise. AA Years is a binary variable equal to one if the year is 2005, zero otherwise. The university experience control consists of a dummy variable equal to one if the applicant has previous university experience, and zero otherwise. We control for age using a quartic function in age. Two-way cluster-robust standard errors (at the major and municipality levels) are shown in parentheses. ${ }^{*}$ significant at $10 \% ; * *$ significant at $5 \%$; $* * *$ significant at $1 \%$. 
Table 9: Performance in Phase 2, 2004-2005 (by ENEM Quartile)

\begin{tabular}{lcccc}
\hline \hline & Q1 & Q2 & Q3 & Q4 \\
Public High School & $-0.137^{* * *}$ & $-0.085^{*}$ & $-0.146^{* * *}$ & $-0.141^{* * *}$ \\
Visible Minority & $(0.026)$ & $(0.044)$ & $(0.037)$ & $(0.020)$ \\
& -0.047 & -0.051 & 0.013 & -0.037 \\
Visible Minority $\times$ Public HS & $(0.059)$ & $(0.039)$ & $(0.050)$ & $(0.051)$ \\
& -0.039 & -0.048 & 0.069 & 0.060 \\
Public HS × AA Years & $(0.066)$ & $(0.072)$ & $(0.063)$ & $(0.096)$ \\
& $0.076^{* *}$ & -0.018 & 0.055 & 0.013 \\
Visible Minority $\times$ AA Years & $(0.031)$ & $(0.030)$ & $(0.051)$ & $(0.031)$ \\
& 0.028 & 0.046 & -0.050 & -0.069 \\
Visible Minority $\times$ Public HS $\times$ AA Years & $(0.062)$ & $(0.041)$ & $(0.080)$ & $(0.069)$ \\
& 0.015 & 0.020 & -0.104 & 0.032 \\
Normalised ENEM Score & $(0.068)$ & $(0.085)$ & $(0.091)$ & $(0.153)$ \\
& $0.385^{* * *}$ & $0.795^{* * *}$ & $1.007^{* * *}$ & $1.115^{* * *}$ \\
Year Fixed Effects & $(0.039)$ & $(0.049)$ & $(0.128)$ & $(0.113)$ \\
Age Controls & Yes & Yes & Yes & Yes \\
Parental Education Controls & Yes & Yes & Yes & Yes \\
University Experience Control & Yes & Yes & Yes & Yes \\
Major Fixed Effects & Yes & Yes & Yes & Yes \\
Municipality Fixed Effects & Yes & Yes & Yes & Yes \\
\hline Number of Observations & Yes & Yes & Yes & Yes \\
Number of Major Clusters & 5,497 & 5,497 & 5,497 & 5,499 \\
Number of Municipality Clusters & 59 & 59 & 58 & 58 \\
\hline \hline
\end{tabular}

Notes: The dependent variable is the normalised Phase 2 test score, excluding Phase 1 performance. This score is normalised such that, every year, the mean and the variance of these scores are 0 and 1 , respectively. The ENEM score is normalised each year using the Sao Paulo state-level average and standard deviation. Applicants were separated into four quartiles (Q1, Q2, Q3, and Q4) based on their ENEM score. Q1 (Q4) is composed of the 25\% of the 2004 and 2005 applicants with the lowest (highest) ENEM scores (25\% of each year). Public High School is a binary variable equal to one if the applicant was enrolled in a Brazilian public school for the duration of her/his secondary education, and zero otherwise. Visible Minority is a binary variable equal to one if the applicant is black, mulatto or native, and zero otherwise. AA Years is a binary variable equal to one if the year is 2005 , zero otherwise. The university experience control consists of a dummy variable equal to one if the applicant has previous university experience, and zero otherwise. We control for age using a quartic function in age. 'Trainees' are excluded. Two-way cluster-robust standard errors (at the major and municipality levels) are shown in parentheses. * significant at $10 \%$; ${ }^{*}$ significant at $5 \%$; ${ }^{* *}$ significant at $1 \%$. 
Table 10: P2 Performance Change, 2004-2005 (Above vs. Below Cutoff, Allowing Different Intercepts and Slopes)

\begin{tabular}{lccc}
\hline \hline Applicant Group & Slope $\Delta$ & Standard Errors & AA Bonus \\
Private HS, Visible Minority, Below Cutoff & 0.036 & $(0.031)$ & 0 pts \\
Private HS, Visible Minority, Above Cutoff & -0.093 & $(0.113)$ & 0 pts \\
Private HS, White, Below Cutoff & 0.000 & $(-)$ & 0 pts \\
Private HS, White, Above Cutoff & -0.018 & $(0.068)$ & 0 pts \\
Public HS, Visible Minority, Below Cutoff & 0.114 & $(0.149)$ & $40 \mathrm{pts}$ \\
Public HS, Visible Minority, Above Cutoff & -0.335 & $(0.419)$ & $40 \mathrm{pts}$ \\
Public HS, White, Below Cutoff & 0.046 & $(0.056)$ & $30 \mathrm{pts}$ \\
Public HS, White, Above Cutoff & -0.094 & $(0.083)$ & $30 \mathrm{pts}$ \\
\hline Applicant Group & Performance $\Delta$ & Standard Errors & AA Bonus \\
Private HS, Visible Minority, Below Cutoff & -0.023 & $(0.063)$ & 0 pts \\
Private HS, Visible Minority, Above Cutoff & 0.050 & $(0.086)$ & 0 pts \\
Private HS, White, Below Cutoff & 0.000 & $(-)$ & 0 pts \\
Private HS, White, Above Cutoff & 0.031 & $(0.054)$ & 0 pts \\
Public HS, Visible Minority, Below Cutoff & -0.063 & $(0.373)$ & $40 \mathrm{pts}$ \\
Public HS, Visible Minority, Above Cutoff & -0.127 & $(0.290)$ & $40 \mathrm{pts}$ \\
Public HS, White, Below Cutoff & -0.024 & $(0.080)$ & $30 \mathrm{pts}$ \\
Public HS, White, Above Cutoff & 0.046 & $(0.067)$ & $30 \mathrm{pts}$ \\
\hline \hline
\end{tabular}

Notes: The slope and performance change estimates are based on the regression estimates found in Table 11, Specification (5). The performance changes are estimated at the median distances to the cutoff for applicants above (-0.8) and below (1.0) the cutoff in 2005. The comparison group consists of white applicants from private high schools with predicted scores under the cutoff score of her/his chosen major. See footnote to Table 11 for more details regarding how we determined whether an applicant was expected to be above or below the cutoff. Standard errors computed using 500 block-bootstrap replications (at the major level) are shown in parentheses. The standard errors are adjusted using a small-sample correction (see Cameron and Miller (2015)). Note that for each replication new sets of predicted scores are computed. The critical values are based on a Student's $t$ distribution with 57 degrees of freedom. ${ }^{*}$ significant at $10 \% ;{ }^{* *}$ significant at $5 \%$; ${ }^{* *}$ significant at $1 \%$. 
Table 11: P2 Performance, 2004-2005 (Heterogeneity-Above vs. Below Cutoff)

\begin{tabular}{|c|c|c|c|c|c|}
\hline & $\overline{(1)}$ & $\overline{(2)}$ & $\overline{(3)}$ & $\overline{(4)}$ & $\overline{(5)}$ \\
\hline Public High School & $\begin{array}{l}-0.305 * * * \\
(0.074)\end{array}$ & $\begin{array}{l}-0.297 * * * \\
(0.076)\end{array}$ & $\begin{array}{l}-0.202^{* * *} \\
(0.067)\end{array}$ & $\begin{array}{l}-0.132 * * * \\
(0.041)\end{array}$ & $\begin{array}{c}-0.161 * * * \\
(0.041)\end{array}$ \\
\hline Visible Minority & $\begin{array}{l}-0.063 \\
(0.094)\end{array}$ & $\begin{array}{l}-0.039 \\
(0.095)\end{array}$ & $\begin{array}{l}-0.043 \\
(0.085)\end{array}$ & $\begin{array}{l}-0.067 \\
(0.070)\end{array}$ & $\begin{array}{l}-0.037 \\
(0.067)\end{array}$ \\
\hline Visible Minority $\times$ Public HS & $\begin{array}{c}0.081 \\
(0.124)\end{array}$ & $\begin{array}{c}0.028 \\
(0.125)\end{array}$ & $\begin{array}{c}0.071 \\
(0.114)\end{array}$ & $\begin{array}{c}0.080 \\
(0.094)\end{array}$ & $\begin{array}{c}0.086 \\
(0.099)\end{array}$ \\
\hline Public HS $\times$ AA Years & $\begin{array}{l}-0.152 \\
(0.123)\end{array}$ & $\begin{array}{l}-0.168 \\
(0.124)\end{array}$ & $\begin{array}{l}-0.098 \\
(0.126)\end{array}$ & $\begin{array}{l}-0.079 \\
(0.132)\end{array}$ & $\begin{array}{l}-0.070 \\
(0.130)\end{array}$ \\
\hline Visible Minority $\times$ AA Years & $\begin{array}{l}-0.086 \\
(0.095)\end{array}$ & $\begin{array}{l}-0.121 \\
(0.097)\end{array}$ & $\begin{array}{l}-0.093 \\
(0.090)\end{array}$ & $\begin{array}{l}-0.022 \\
(0.081)\end{array}$ & $\begin{array}{l}-0.059 \\
(0.087)\end{array}$ \\
\hline Visible Minority $\times$ Public HS $\times$ AA Years & & $\begin{array}{c}0.342 \\
(0.254)\end{array}$ & $\begin{array}{c}0.297 \\
(0.282)\end{array}$ & $\begin{array}{c}0.333 \\
(1.013)\end{array}$ & $\begin{array}{l}-0.047 \\
(0.498)\end{array}$ \\
\hline Normalised ENEM Score & $\begin{array}{c}1.117^{* * *} \\
(0.079)\end{array}$ & $\begin{array}{c}1.117 * * * \\
(0.079)\end{array}$ & $\begin{array}{c}1.128^{* * *} \\
(0.078)\end{array}$ & $\begin{array}{c}0.716^{* * *} \\
(0.031)\end{array}$ & $\begin{array}{c}0.737 * * * \\
(0.031)\end{array}$ \\
\hline Above Cutoff & $\begin{array}{c}0.350 \\
(0.243)\end{array}$ & $\begin{array}{c}0.356 \\
(0.241)\end{array}$ & $\begin{array}{c}0.303 \\
(0.209)\end{array}$ & $\begin{array}{c}0.009 \\
(0.059)\end{array}$ & $\begin{array}{l}-0.009 \\
(0.063)\end{array}$ \\
\hline Above Cut. $\times$ Public HS & $\begin{array}{l}-0.344^{*} \\
(0.201)\end{array}$ & $\begin{array}{l}-0.360^{*} \\
(0.202)\end{array}$ & $\begin{array}{l}-0.233 \\
(0.158)\end{array}$ & $\begin{array}{c}0.022 \\
(0.107)\end{array}$ & $\begin{array}{c}0.094 \\
(0.113)\end{array}$ \\
\hline Above Cut. $\times$ Vis. Min. & $\begin{array}{l}-0.297^{*} \\
(0.178)\end{array}$ & $\begin{array}{l}-0.379^{*} \\
(0.195)\end{array}$ & $\begin{array}{l}-0.106 \\
(0.194)\end{array}$ & $\begin{array}{c}0.028 \\
(0.190)\end{array}$ & $\begin{array}{c}0.006 \\
(0.176)\end{array}$ \\
\hline Above Cut. $\times$ Vis. Min. $\times$ Public HS & $\begin{array}{l}-0.120 \\
(0.126)\end{array}$ & $\begin{array}{l}-0.020 \\
(0.232)\end{array}$ & $\begin{array}{l}-0.048 \\
(0.219)\end{array}$ & $\begin{array}{c}0.035 \\
(0.290)\end{array}$ & $\begin{array}{c}0.111 \\
(0.296)\end{array}$ \\
\hline Above Cut. $\times$ AA Years & $\begin{array}{l}-0.305 \\
(0.263)\end{array}$ & $\begin{array}{c}-0.314 \\
(0.261)\end{array}$ & $\begin{array}{l}-0.243 \\
(0.224)\end{array}$ & $\begin{array}{c}0.034 \\
(0.072)\end{array}$ & $\begin{array}{c}0.052 \\
(0.072)\end{array}$ \\
\hline Above Cut. $\times$ Public HS $\times$ AA Years & $\begin{array}{l}0.457^{* *} \\
(0.223)\end{array}$ & $\begin{array}{l}0.487^{* * *} \\
(0.221)\end{array}$ & $\begin{array}{c}0.279 \\
(0.194)\end{array}$ & $\begin{array}{c}0.073 \\
(0.171)\end{array}$ & $\begin{array}{c}0.024 \\
(0.174)\end{array}$ \\
\hline Above Cut. $\times$ Vis. Min. $\times$ AA Years & $\begin{array}{c}0.357^{* *} \\
(0.178)\end{array}$ & $\begin{array}{l}0.466^{* *} \\
(0.207)\end{array}$ & $\begin{array}{c}0.217 \\
(0.216)\end{array}$ & $\begin{array}{c}0.034 \\
(0.204)\end{array}$ & $\begin{array}{c}0.018 \\
(0.189)\end{array}$ \\
\hline Above Cut. $\times$ Vis. Min. $\times$ Pub. HS $\times$ AA Years & & $\begin{array}{l}-0.418 \\
(0.324)\end{array}$ & $\begin{array}{l}-0.333 \\
(0.328)\end{array}$ & $\begin{array}{l}-0.462 \\
(1.051)\end{array}$ & $\begin{array}{l}-0.120 \\
(0.530)\end{array}$ \\
\hline Distance to Cutoff & $\begin{array}{c}0.138^{* * *} \\
(0.047)\end{array}$ & $\begin{array}{c}0.139 * * * \\
(0.047)\end{array}$ & $\begin{array}{c}0.135 * * * \\
(0.045)\end{array}$ & $\begin{array}{l}-0.004 \\
(0.007)\end{array}$ & $\begin{array}{l}-0.003 \\
(0.006)\end{array}$ \\
\hline Dist. to Cut. $\times$ Public HS & $\begin{array}{l}-0.007 \\
(0.021)\end{array}$ & $\begin{array}{l}-0.008 \\
(0.021)\end{array}$ & $\begin{array}{l}-0.003 \\
(0.019)\end{array}$ & $\begin{array}{l}0.006 \\
(0.007)\end{array}$ & $\begin{array}{c}0.011 \\
(0.008)\end{array}$ \\
\hline Dist. to Cut. $\times$ Vis. Min. & $\begin{array}{c}0.002 \\
(0.019)\end{array}$ & $\begin{array}{l}-0.001 \\
(0.019)\end{array}$ & $\begin{array}{c}0.008 \\
(0.018)\end{array}$ & $\begin{array}{c}0.009 \\
(0.012)\end{array}$ & $\begin{array}{l}0.003 \\
(0.015)\end{array}$ \\
\hline Dist. to Cut. $\times$ Vis. Min. $\times$ Public HS & $\begin{array}{l}-0.022 \\
(0.028)\end{array}$ & $\begin{array}{l}-0.016 \\
(0.028)\end{array}$ & $\begin{array}{l}-0.020 \\
(0.027)\end{array}$ & $\begin{array}{l}-0.020 \\
(0.017)\end{array}$ & $\begin{array}{l}-0.019 \\
(0.023)\end{array}$ \\
\hline Dist. to Cut. $\times$ AA Years & $\begin{array}{c}0.049 \\
(0.031)\end{array}$ & $\begin{array}{c}0.050 \\
(0.031)\end{array}$ & $\begin{array}{l}0.057^{*} \\
(0.030)\end{array}$ & $\begin{array}{l}-0.004 \\
(0.016)\end{array}$ & $\begin{array}{c}0.019 \\
(0.015)\end{array}$ \\
\hline Dist. to Cut. $\times$ Public HS $\times$ AA Years & $\begin{array}{c}0.038 \\
(0.038)\end{array}$ & $\begin{array}{c}0.034 \\
(0.037)\end{array}$ & $\begin{array}{c}0.023 \\
(0.044)\end{array}$ & $\begin{array}{l}0.050 \\
(0.051)\end{array}$ & $\begin{array}{c}0.046 \\
(0.056)\end{array}$ \\
\hline Dist. to Cut. $\times$ Vis. Min. $\times$ AA Years & $\begin{array}{c}0.026 \\
(0.028)\end{array}$ & $\begin{array}{c}0.022 \\
(0.034)\end{array}$ & $\begin{array}{l}0.025 \\
(0.038)\end{array}$ & $\begin{array}{l}0.026 \\
(0.024)\end{array}$ & $\begin{array}{c}0.036 \\
(0.031)\end{array}$ \\
\hline Dist. to Cut. $\times$ Vis. Min. $\times$ Pub. HS $\times$ AA Years & & $\begin{array}{l}-0.044 \\
(0.084)\end{array}$ & $\begin{array}{l}-0.061 \\
(0.093)\end{array}$ & $\begin{array}{l}-0.025 \\
(0.240)\end{array}$ & $\begin{array}{c}0.032 \\
(0.147)\end{array}$ \\
\hline Distance $\times$ Above Cutoff & $\begin{array}{c}0.137 \\
(0.106)\end{array}$ & $\begin{array}{c}0.134 \\
(0.106)\end{array}$ & $\begin{array}{c}0.113 \\
(0.098)\end{array}$ & $\begin{array}{c}0.009 \\
(0.072)\end{array}$ & $\begin{array}{l}-0.001 \\
(0.073)\end{array}$ \\
\hline Dist. $\times$ Above $\times$ Public HS & $\begin{array}{l}-0.060 \\
(0.095)\end{array}$ & $\begin{array}{l}-0.043 \\
(0.107)\end{array}$ & $\begin{array}{l}-0.003 \\
(0.092)\end{array}$ & $\begin{array}{c}0.049 \\
(0.108)\end{array}$ & $\begin{array}{c}0.072 \\
(0.116)\end{array}$ \\
\hline Dist. $\times$ Above $\times$ Vis. Min & $\begin{array}{l}-0.112 \\
(0.083)\end{array}$ & $\begin{array}{l}-0.085 \\
(0.117)\end{array}$ & $\begin{array}{c}0.047 \\
(0.137)\end{array}$ & $\begin{array}{c}0.054 \\
(0.135)\end{array}$ & $\begin{array}{c}0.054 \\
(0.122)\end{array}$ \\
\hline Dist. $\times$ Above $\times$ Vis. Min. $\times$ Public HS & $\begin{array}{c}0.067 \\
(0.052)\end{array}$ & $\begin{array}{l}-0.105 \\
(0.226)\end{array}$ & $\begin{array}{l}-0.058 \\
(0.194)\end{array}$ & $\begin{array}{c}0.166 \\
(0.550)\end{array}$ & $\begin{array}{c}0.266 \\
(0.464)\end{array}$ \\
\hline Dist. $\times$ Above $\times$ AA Years & $\begin{array}{l}-0.222^{*} \\
(0.125)\end{array}$ & $\begin{array}{l}-0.220^{*} \\
(0.124)\end{array}$ & $\begin{array}{l}-0.194^{*} \\
(0.110)\end{array}$ & $\begin{array}{l}-0.018 \\
(0.069)\end{array}$ & $\begin{array}{l}-0.018 \\
(0.068)\end{array}$ \\
\hline Dist. $\times$ Above $\times$ Public HS $\times$ AA Years & $\begin{array}{l}0.105 \\
(0.104)\end{array}$ & $\begin{array}{c}0.091 \\
(0.112)\end{array}$ & $\begin{array}{c}0.030 \\
(0.100)\end{array}$ & $\begin{array}{l}-0.094 \\
(0.114)\end{array}$ & $\begin{array}{l}-0.123 \\
(0.124)\end{array}$ \\
\hline Dist. $\times$ Above $\times$ Vis. Min. $\times$ AA Years & $\begin{array}{c}0.083 \\
(0.084)\end{array}$ & $\begin{array}{c}0.064 \\
(0.119)\end{array}$ & $\begin{array}{l}-0.075 \\
(0.132)\end{array}$ & $\begin{array}{l}-0.105 \\
(0.136)\end{array}$ & $\begin{array}{l}-0.111 \\
(0.125)\end{array}$ \\
\hline Dist. $\times$ Above $\times$ Vis. Min. $\times$ Pub. HS $\times$ AA Years & & $\begin{array}{c}0.219 \\
(0.236)\end{array}$ & $\begin{array}{c}0.213 \\
(0.222)\end{array}$ & $\begin{array}{l}-0.059 \\
(0.595)\end{array}$ & $\begin{array}{l}-0.197 \\
(0.498)\end{array}$ \\
\hline Year Fixed Effects & Yes & Yes & Yes & Yes & Yes \\
\hline Age and Gender Controls & No & No & Yes & Yes & Yes \\
\hline Parental Education Controls & No & No & Yes & Yes & Yes \\
\hline University Experience Control & No & No & Yes & Yes & Yes \\
\hline Major Fixed Effects & No & No & No & Yes & Yes \\
\hline Municipality Fixed Effects & No & No & No & No & Yes \\
\hline Number of Observations & 21,259 & 21,259 & 21,259 & 21,259 & 21,259 \\
\hline Number of Major Clusters & 58 & 58 & 58 & 58 & 58 \\
\hline
\end{tabular}

Notes: The dependent variable is the normalised Phase 2 test score, excluding Phase 1 performance. This score is normalised such that, every year, the mean and the variance of these scores are 0 and 1 , respectively. The ENEM score is normalised each year using the Sao Paulo state-level average and standard deviation. Predicted Distance to Cutoff is estimated using regressions using 2004 second stage candidates only to get a predicted second-stage score (for both 2004 and 2005 applicants) and the previous year's cutoffs (2003 for 2004 and 2004 for 2005). Predicted Distance to Cutoff is measure as last year's cutoff minus the predicted score and normalised using the standard deviations of these differences (computed for every major-choice/year combination). Above Cutoff is equal to 1 if the predicted score including the bonus points (for eligible candidates) is above last year's cutoff, and zero otherwise. Each specification has its own vector of Predicted Distance to Cutoff values given that the predicted scores are computed using different sets of regressors. Public High School is a binary variable equal to one if the applicant was enrolled in a Brazilian public school for the duration of her/his secondary education, and zero otherwise. Visible Minority is a binary variable equal to one if the applicant is black, mulatto or native, and zero otherwise. AA Years is a binary variable equal to one if the year is 2005, zero otherwise. The university experience control consists of a dummy variable equal to one if the applicant has previous university experience, and zero otherwise. We control for age using a quartic function in age. 'Trainees' are excluded. Standard errors computed using 500 block-bootstrap replications (at the major level) are shown in parentheses. The standard errors are adjusted using a small-sample correction (see Cameron and Miller (2015)). Note that for each replication new sets of predicted scores are computed. The critical values are based on a Student's $t$ distribution with 57 degrees of freedom. ${ }^{*}$ significant at $10 \%$; ** significant at $5 \%$; ** significant at $1 \%$. 